\title{
In Vivo Visualizaton of Pre- and Postsynaptic Changes During Synapse Elimination in Reinnervated Mouse Muscle
}

\author{
Mark M. Rich and Jeff W. Lichtman \\ Department of Anatomy and Neurobiology, Washington University School of Medicine, St. Louis, Missouri 63110
}

Using a vital nerve terminal dye (4-Di-2-ASP) and fluorescently tagged $\alpha$-bungarotoxin to stain postsynaptic acetylcholine (ACh) receptors, we viewed the same muscle fibers at multiple times in the sternomastoid muscle of living mice during the process of reinnervation following nerve crush. Soon after axons reenter the muscle, they precisely reoccupy the original endplate sites. However, in contrast to normal adult muscle, during the first several weeks of reinnervation, anatomical and physiological measures show that many of the endplate sites are innervated by more than one axon. Typically, one axon reinnervates the original endplate site by growing up the old Schwann cell tube while another originates as a sprout from a nearby endplate. Within 2 weeks after reinnervation nerve terminal staining shows that most of the sprouts have regressed and physiological evidence of multiple Innervation has returned to the normal low level. By repeatedly observing the same endplates during the period of synapse elimination, we could directly view this phenomenon. At some endplates, nerve terminal boutons in one region of the endplate were eliminated at the same time a sprout entering that area regressed. These unoccupied sites seemed permanently eliminated as they are not subsequently occupied by sprouts from the axon remaining at the endplate. We were surprised to find that there is a corresponding permanent loss of ACh receptors within the muscle fiber membrane precisely underneath the eliminated nerve terminals. The decrease in receptors at sites of synapse elimination is due to both a selective loss of ACh receptors already incorporated into these sites and to a lack of insertion of new receptors at the same regions. These sites of pre- and postsynaptic loss, however, maintain cholinesterase staining in the basal lamina for long periods. Control experiments showed that endplates that were permanently denervated, incompletely reoccupied by reinnervating axons, or stained and viewed multiple times in normal muscle do not lose postsynaptic receptor regions. Interestingly, receptors appear to be eliminated before there is any obvious change in the staining of the overlying nerve terminal. Because of the lag between receptor and nerve terminal loss, we could predict which synaptic boutons would be elimi-

Received May 12, 1988; revised Aug. 26, 1988; accepted Sept. 26, 1988.

We wish to thank Drs. R. Balice-Gordon, G. Fischbach, G. Reiness, and J. Sanes for helpful comments. Supported by grants from the NIH, MDA, a McKnight Neuroscience Development Award to J.W.L., and Medical Scientist Training Grant 5 T32 GM07200 to M.M.R.

Correspondence should be addressed to Jeff W. Lichtman, Department of Anatomy and Neurobiology, Washington University School of Medicine, 660 South Euclid Avenue, Box 8108 , St. Louis, MO 63110.

Copyright (C) 1989 Society for Neuroscience $0270-6474 / 89 / 051781-25 \$ 02.00 / 0$ nated by looking for lightly stained receptor regions. One interpretation of these data is that the removal or redistribution of relevant postsynaptic molecules by one innervating axon may instigate the elimination of competing terminals.

The competitive interactions between neurons that lead to synapse loss are not understood. In the past, a major difficulty was that an individual synapse could not be viewed more than once, necessitating inferences from a series of static images of different synapses about the dynamic events occurring at each synapse. In order to better understand synapse elimination, we have repeatedly viewed individual synaptic sites in living adult mice during the elimination of multiple innervation that occurs after reinnervation.

There are several lines of anatomical and physiological evidence showing that during reinnervation of adult muscle, as in development, endplates normally innervated by a single motor axon are multiply innervated (Tate and Westerman, 1973; Jansen and Van Essen, 1975; McArdle, 1975; Letinsky et al., 1976; Rotshenker and McMahan, 1976; Gorio et al., 1983; Werle and Herrera, 1986). From most of these studies it appears that when muscle fibers are multiply innervated during reinnervation, the axons converge on the same endplate site. In fact, in frogs at least, multiple axons may even reside in the same synaptic gutter (Letinsky et al., 1976; Rotshenker and McMahan, 1976). In some animals, this multiple innervation of individual muscle fibers is unstable. For example, in rats the incidence of multiple innervation drops to near control levels 8 weeks after reinnervation (McArdle, 1975; Gorio et al., 1983).

In situations in which synaptic competition takes place, the synaptic connections of some axons survive or even proliferate while the synapses of other axons innervating the same target cell are eliminated (for review, see Purves and Lichtman, 1985). Most of the postulated mechanisms put forward to explain synaptic competition require that one axon makes the nearby environment of another axon "uninhabitable" either by depriving it of some necessary molecule (e.g., by competition for a trophic factor in limited supply: Changeux and Dauchin, 1976; Purves, 1977) or by "poisoning" it (e.g., by inducing the secretion of a noxious substance: O'Brien et al., 1984; Connold et al., 1986). One problem in understanding the mechanism of this rearrangement is that the relative importance of the pre- and postsynaptic cells in this process is not known. Thus, it is uncertain whether the axons compete among themselves for a rather passive target or, alternatively, whether the postsynaptic cell mediates the competition, dictating which synapses persist and which are eliminated. An intermediate possibility is that one axon instigates the elimination of another axon but uses the postsynaptic cell as intermediary. 
That the postsynaptic cell is in some way involved in the outcome of synaptic competition is suggested by several results in which changes in postsynaptic activity levels, independent of presynaptic activity, alter the rate of synaptic competition (Srihari and Vrbova, 1978; Duxson, 1982; Ding et al., 1983; Thompson, 1983; for review, see Thompson, 1985). Furthermore, in one muscle, synapse elimination does not occur on postsynaptic muscle cells that are unable to fire action potentials while synaptic competition completely eliminates multiple innervation on adjacent muscle fibers capable of regenerative activity (Lichtman et al., 1985).

That the postsynaptic cell is involved is also indicated by the fact that competition only occurs between synapses situated on the same postsynaptic cell. Thus, 2 synaptic endings from different axons may be very close to each other and stably maintained when they are on adjacent postsynaptic cells (see, for example, Lichtman, 1980). On the other hand, 2 innervation sites cannot reside near each other on the same target cell (Brown et al., 1976). The likely explanation for this difference is that the postsynaptic cell is an intermediary in the process of synaptic maintenance; if the postsynaptic cell is involved, competition will only take place when synapses are established on the same target cell (Kuffler et al., 1980). The way in which a muscle cell might act as intermediary in synaptic competition, however, is uncertain.

In the work described here, we repeatedly viewed in living animals the location of nerve terminals and the distribution of acetylcholine $(\mathrm{ACh})$ receptors in the postsynaptic muscle fiber membrane during the period of synapse elimination. One question we wished to address was whether presynaptic axons compete to occupy the same postsynaptic regions. Our results suggest that the site vacated by a losing lost axon is not reoccupied by the remaining axon.

At endplates undergoing synapse elimination we found a permanent loss of postsynaptic receptors that was coextensive with the loss of eliminated nerve terminals. This is the first direct evidence of a change in the postsynaptic cell related to the synapse elimination process. To pursue the possibility that the postsynaptic cell might mediate synapse elimination, we have studied the temporal relation between loss of postsynaptic receptors and the loss of overlying nerve terminals. Our results show that postsynaptic receptor elimination can be detected at endplates before nerve terminal loss. This may mean that elimination of relevant postsynaptic molecules precedes, and possibly initiates, the removal of overlying nerve terminals. Some of these results have been briefly presented (Rich and Lichtman, 1986).

\section{Materials and Methods}

Denervation of the sternomastoid muscle. Young adult female mice (CF1 strain, 15-25 gm) were anesthetized with an i.p. injection of chloral hydrate $(0.6 \mathrm{gm} / \mathrm{kg})$; the neck was then shaved, and a midline incision was made from the apex of the mandible to the sternal notch. The left sternomastoid muscle was exposed by lateral reflection of the salivary glands. In those mice in which the endplates were to be viewed at the time of denervation, the animal was intubated with an endotracheal tube, and respirations were controlled with a Harvard small animal respirator. The nerve to the sternomastoid muscle was exposed at its point of emergence from under the digastric muscle and lesioned in 1 of 3 ways. In one set of animals (single nerve crush; $n=67$ for anatomical studies, $n=20$ for physiology), the nerve was crushed with a forceps until clear at 2 adjacent sites. In the second set (double nerve crush; $n$ $=75$ for anatomical studies, $n=17$ for physiological studies), the nerve was crushed as above and the animal was allowed to recover for $4 \mathrm{~d}$, at which time the wound was reopened and the nerve was again crushed in the same manner. This method of double crushing delayed the return of axons by approximately $3 \mathrm{~d}$. Because axons first return to the muscle 4-5 d after a single nerve crush and 3-4 d after the second crush of a double nerve crush lesion, we discuss double crush lesions in terms of days after the second crush. This synchronizes the reinnervation following single and double crushes to the same time scale. In a third group of animals, the nerve was cut at the same site as the nerve crushes and the 2 ends were allowed to separate $(n=12$ for analomical studies, $n$ $=11$ for physiological studies). The wound was then closed and the animal allowed to recover. For permanent denervations $(n=2)$, a 4 $\mathrm{mm}$ segment of the nerve to the sternomastoid muscle was removed. In these animals, when $\mathrm{ACh}$ receptors were subsequently viewed, the muscle was also stained with 4-Di-2-ASP and viewed to verify that axons had not returned.

Measurement of multiple innervation. The incidence of multiple innervation was assessed electrophysiologically in sternomastoid muscles dissected out of the animal with the nerve supply intact and placed in oxygenated Dulbecco's Modified Eagle's Medium (DME). The nerve to the muscle was drawn into a tight-fitting suction electrode and was stimulated $(0-10 \mathrm{~V}, 1 \mathrm{msec}$ duration) while recording intracellularly near the muscle fiber endplates. Muscle contraction was eliminated by cutting the muscle fibers on either side of the endplate band (Barstad and Lilleheil, 1968). As increasing voltage was applied to the nerve, in some fibers multiple inputs were detected as steps in the intracellularly recorded endplate potential (Kedfern, 1970). To insure that small inputs were not missed, only muscle fibers with resting potentials greater than $-30 \mathrm{mV}$ were used. In the cut muscle fiber preparations, the majority of fibers had resting potentials between -30 and $-40 \mathrm{mV}$. In most fibers, miniature endplate potentials were observed, which argued that even very small inputs could be resolved.

Anatomical assessment of multiple innervation was made by staining the muscle with 4-Di-2-ASP (Lichtman et al., 1987; Magrassi et al., 1987). An estimate of the relative incidence of multiply innervated endplates at different times after nerve crush was obtained by calculating the percentage of endplates that were innervated by a branch of the nerve and also connected to another endplate by a terminal sprout. We then divided this percentage by 2 because one of each pair of endplates connected by a sprout is presumably the source of the sprout and does not receive a second input. It was often not possible to tell which endplate was the source and which was the recipient of a sprout. The above technique is at best a rough estimate of multiple innervation because it only assesses multiple innervation via endplate to endplate sprouts that were usually clearly visible. Multiple axons entering the endplate site via the old Schwann cell tube could not be distinguished with this staining technique. Further, this calculation assumes that the sprout arising from one endplate has a functional input to the second endplate. Finally, it assumes that both endplates are not innervated by 2 branches of the same axon. Although these assumptions prevent us from obtaining an absolute measure for the incidence of multiple innervation, this measure appears to be a reliable index because it parallels our electrophysiological assessment of multiple innervation.

Silver stains of neuromuscular junctions. A modified combined stain for nerve terminals using silver (see Kiernan, 1981) and cholinesterase (Oda, 1984) was used to obtain an independent assessment of multiple innervation that could be used to evaluate the number of junctions with 2 axons entering by the same Schwann cell tube. Briefly, the tissue was fixed in formalin, teased into bundles, stained for cholinesterase, dehydrated to xylene and rehydrated. Following a $40 \mathrm{~min}$ incubation in $20 \% \mathrm{AgNO}_{3}$, the tissue was developed under visual observation in a reducing solution of hydroquinone and sodium sulfite (Kiernan, 1981), dehydrated to xylene, and mounted in permount.

Repeated visualization of individual nerve terminals. The method outlined in Lichtman et al. (1987) was followed except that relocating the same endplate site during reinnervation was more difficult. At short intervals after nerve damage, axons had either not returned or were only beginning to reinnervate the muscle. Furthermore, following nerve damage, muscle atrophy changed the absolute spacing of endplates. It was, however, still generally possible to relocate original endplate sites positively at multiple times. A map of the relative locations of endplates was made taking advantage of the fact that the vital dye also stained the branching pattern of the nerve. However, even at short times following denervation before the axons had returned, the distinct pattern of muscle fiber nuclei at each endplate site and the lightly staining vacated Schwann cell tubes allowed positive reidentification of original sites (see Fig. 2).

In contrast to earlier in vivo studies in which the same endplate was never viewed more than twice (e.g., Lichtman et al., 1987), the same 
endplate site was often relocated up to 5 separate times with intervals between views ranging from 2 to $80 \mathrm{~d}$. The procedure was generally innocuous, with an overall mortality rate of less than $5 \%$.

Visualization of endplate ACh receptor distribution and nerve terminals. Purified $\alpha$-bungarotoxin (Sigma, St. Louis) was rhodaminated using the method of Ravdin and Axelrod (1977). Receptors were stained by a $3 \mathrm{~min}$ incubation of the sternomastoid muscle in sterile saline (lactated Ringer's solution, Travenol) containing approximately $4 \mu \mathrm{g} /$ $\mathrm{ml}$ rhodaminated $\alpha$-bungarotoxin and $1 \mathrm{mg} / \mathrm{ml}$ BSA. This staining procedure leads to an approximately 50\% saturation of the ACh receptors as estimated by quantitating the brightness of the receptor staining (see below). The muscle was then rinsed in Ringer's, and digital images of the endplates were obtained with fluorescence optics (Leitz N2.1 cube; 515-560 $\mathrm{nm}$ excitation and $580 \mathrm{~nm}$ suppression) using a SIT camera connected to a digital image processor (Trapix, Image Recognition Concepts). The coverslip was then raised and the muscle incubated for 3 min, in a $10 \mathrm{~mm}$ solution of 4-Di-2-ASP (Magrassi et al., 1987). The dye was rinsed out and the coverslip lowered. The terminals of the selected endplates were viewed using fluorescence optics (Leitz I 2 cube; $450-490 \mathrm{~nm}$ excitation and $515 \mathrm{~nm}$ suppression), and the images of nerve terminals were also stored digitally. The nerve terminal and receptor images were enhanced, aligned, and photographed using the image processor and software (IMAGR) developed locally by J. Voyvodic and with programs written by W. Sunderland. At subsequent viewing of endplates, the whole procedure outlined above was repeated.

This double staining showed a precise alignment between nerve terminals and $\mathrm{ACh}$ receptors (see, for example, Figs. 6, 11). It is possible, however, that some nerve processes do not stain with 4-Di-2-ASP (see Robbins and Polak, 1988), even though sprouts are well stained with this dye (see, for example, Fig. 5). Unstained processes, if they are present, are unlikely to be of much importance in these experiments. The dye staining we do see accounts for all the functional inputs because it completely and consistently overlies all the $\mathrm{ACh}$ receptors.

Quantitation of ACh receptor loss and addition. To determine whether the receptor distribution of an endplate had changed, the distribution of the receptors before denervation was compared with that after reinnervation. The initial image of the receptor distribution at an endplate was divided into a number of $5 \mu \mathrm{m}$ segments. Each segment was scored as either present or absent at the second viewing. Segments on the edge of the muscle fiber that could not be seen clearly at either the first or second viewing were excluded. Only endplates in which over $10 \%$ of the receptor length was clearly absent at the second viewing were scored as having changed significantly. Because additions of new receptor areas were rare during reinnervation and always small $(<10 \%$ of the total receptor area), they were not included in estimates of endplate change.

Prospective studies of singly and multiply innervated endplates. The nerve to the sternomastoid muscle of anesthetized mice was crushed and the wound closed without viewing the endplates. Nine days later the mice were reanesthetized, and the muscle was exposed and stained with 4-Di-2-ASP. By visual inspection, endplates were divided into those that were only innervated by axons entering through the old Schwann cell tube (could not be classified as singly or multiply innervated) and those that were clearly innervated through the Schwann cell tube, but also connected to other nearby endplates by sprouts (half or more of which should be multiply innervated). After viewing the nerve terminals, the ACh receptors were stained with rhodaminated $\alpha$-bungarotoxin and digitized images of the endplates were stored. The wound was then closed and the animal allowed to recover. Two weeks later the mouse was reanesthetized, the muscle reexposed, and the nerve terminals and receptors again visualized. To decidc objectivcly whether an endplate had changed, 2 images of the receptors (before and after the period of synapse elimination) were viewed by an investigator who did not know whether the endplate had been scored as unclassified or multiply innervated (by 4-Di-2-ASP staining) at the first viewing.

Fate of $A C h$ receptors already inserted in the muscle membrane. ACh receptors were labeled in vivo by applying a solution containing $4 \mu \mathrm{g} /$ $\mathrm{ml}$ rhodaminated $\alpha$-bungarotoxin as described above. After visualizing the endplate sites, the sternomastoid was denervated by a nerve crush. The wound was then closed and the animal allowed to recover. After $17 \mathrm{~d}$ the wound was reopened and the receptor sites were relocated without the application of any new stain. Although the receptor staining at the endplates was faint, the former sites could still be easily relocated. After imaging the endplates, the muscle was stained with new rhodaminated $\alpha$-bungarotoxin to visualize ncwly inserted receptors.

Fluorescent immunostaining of cholinesterase. Muscles were incubated with rabbit antiserum to human erythrocyte AChE (courtesy Dr.
T. Rosenberry, Case Western Reserve). After rinsing, the muscle was incubated in a solution containing fluoresceinated second antibody (goat anti-rabbit IgG, Atlantic Antibodies). Because bungarotoxin staining lines up with cholinesterase staining in normal muscle (see Fig. 19), the distribution of cholinesterase can be inferred from bungarotoxin staining in normal muscles. We used this colocalization to follow changes in cholinesterase distribution during reinnervation. Thus, at the initial viewing only receptors were stained. At second viewing (after reinnervation), both cholinesterase and $\mathrm{ACh}$ receptor distributions were imaged. In this way, we could determine if the distribution of either the receptors or esterase had changed without using 2 exposures to the antibody.

Quantitation of intensity of receptor staining. The intensity of rhodaminated $\alpha$-bungarotoxin staining was quantitated by using the SIT camera and digital image processor. After storing an image of receptors stained with toxin ( $4 \mu \mathrm{g} / \mathrm{ml}$ for $3 \mathrm{~min}$ ), the intensity of each pixel in the image was measured. Using a series of neutral density filters we found that the intensity of each spot measured by the camera was linearly related to the illumination intensity. To determine the percentage of receptors labeled by our $3 \mathrm{~min}$ staining procedure we further stained the same endplates with rhodamined $\alpha$-bungarotoxin $(4 \mu \mathrm{g} / \mathrm{ml})$ for an additional $1 \mathrm{hr}$ to saturate the receptors. After the second application of toxin, we determined the new average intensity of each pixel at the endplates viewed previously using the same illumination intensity as used in the first viewing. We found that pixel intensities following the first staining were only $50 \%$ as bright as after the $1 \mathrm{hr}$ staining. Thus, the proportion of receptors we are labeling is approximately $50 \%$.

At endplates with faint receptor areas the intensity of the faint area was estimated by inserting neutral density filters into the light path and diminishing the intensity of nearby bright areas until the bright areas were as faint as the areas of low receptor density had been at the original light intensity.

\section{Results}

\section{Time course of reinnervation of the sternomastoid muscle}

We studied the reinnervation of muscle fibers in the sternomastoid muscle of mice following damage to the muscle nerve approximately $3 \mathrm{~mm}$ from the muscle. Three methods of denervation were used, which resulted in different time courses of reinnervation. By staining the muscle with 4-Di-2-ASP and recording intracellularly from fibers, we found that a single crush of the nerve caused the most rapid return of axons (4-5 d). To delay the return of axons we crushed the nerve a second time at the same site, the second crush coming $4 \mathrm{~d}$ after the first. This delayed the return of the nerve by approximately $3 \mathrm{~d}$. Finally, we cut the nerve and allowed the ends to separate slightly. Reinnervation was highly variable with this method. In the best cases the nerve reinnervated the muscle about 4 weeks after the cut. In some animals, however, the nerve returned much more slowly and many fibers did not become reinnervated.

\section{Physiological evidence of transient multiple innervation during reinnervation.}

After the axons returned to the sternomastoid muscle, multiple innervation could be detected by intracellularly recording from individual muscle fibers. Gradual increases in the strength of stimulation to the nerve caused multiple steps in the endplate potential. Nine days following a single crush lesion of the nerve, $10 \%$ of the fibers $(12 / 126)$ had more than one input. This was the maximal level of multiple innervation observed at any time during reinnervation following single crush. The percentage of multiply innervated fibers declined rapidly, and by $15 \mathrm{~d}$ after single nerve crush only $2 \%$ of the fibers $(2 / 107)$ were multiply innervated (Fig. 1). This low level of multiple innervation was maintained for at least $35 \mathrm{~d}$ and was not significantly different from age-matched control muscles, where slightly less than $1 \%$ of the fibers $(1 / 120)$ had multiple inputs. Thus, synapse elimi- 

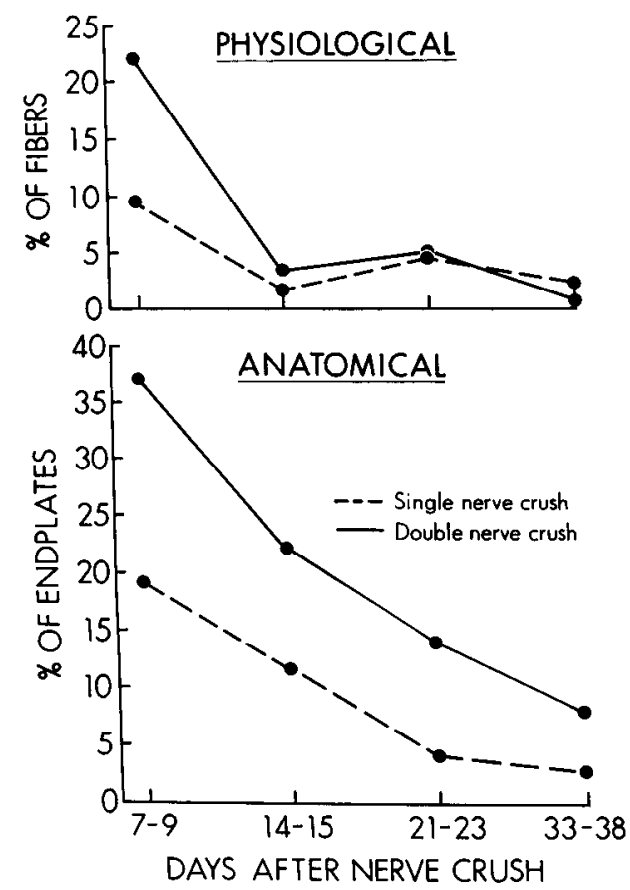

Figure 1. Percentage of muscle fibers multiply innervated at various times following single and double crush lesions of the nerve. Top, The percentage of muscle fibers that appear multiply innervated by intracellular recording rapidly declines following reinnervation. At longer times, only low levels of multiple innervation are maintained. Each point represents 100-120 muscle fibers. Bottom, The percentage of endplates apparently multiply innervated by sprouts falls off following reinnervation. Approximately twice as many endplates appear anatomically and physiologically multiply innervated following a double crush lesion of the nerve than following a single nerve crush. Each point represents 75-150 endplates.

nation is essentially complete $11 \mathrm{~d}$ after the nerve has returned to the muscle ( $15 \mathrm{~d}$ after nerve crush).

The peak percentage of multiply innervated endplates was greater when the muscle was denervated in other ways. When the nerve to the sternomastoid was recrushed $4 \mathrm{~d}$ after the initial lesion (before the axons had returned to the muscle), twice as much multiple innervation was observed. Nine days after the second crush of a double-crush lesion, $22 \%$ of the muscle fibers recorded from (23/109) had 2 steps in their endplate potential. As following single nerve crush, the percentage of multiply innervated fibers rapidly declined. At $15 \mathrm{~d}$ after second nerve crush, only $4 \%$ of the fibers (4/107) were multiply inncrvated (Fig. 1).

Following nerve cut, the time course of reinnervation was too variable for a systematic study of synapse elimination. Still, in some animals we found as many as $56 \%$ of the muscle fibers $(13 / 25)$ were multiply innervated one month after nerve cut and the rest singly innervated. At long times, lower levels of multiple innervation were seen, suggesting that synapse elimination had occurred. Even at 99 d, however, approximately $12 \%$ of the muscle fibers $(6 / 50)$ had multiple steps in their endplate potential.

\section{Accurate reoccupation of the old endplate site}

To follow the reinnervation of individual muscle fibers directly we viewed the same muscle fibers and the axons that innervated them before and at various times after reinnervation. When we viewed endplates before and during reinnervation, we found that the original endplate site was always the site of reinnervation (40/40). An example of one such endplate is shown in Figure 2, which was viewed 5 separate times over $2^{1 / 2}$ months. Before nerve crush, an axon was seen entering the endplate and branching (Fig. 2A). Two days after the nerve to the sternomastoid was crushed, the endplate was relocated (Fig. $2 B$ ). Although the nerve had degenerated and no nerve terminal staining was present, we were confident that this was the same endplate site because of the distinctive arrangement of muscle nuclei and the presence of the original Schwann cell tube. Nine days later (11 d after nerve crush), the same endplate was again relocated. An axon (probably not the original axon) had reoccupied the endplate by growing through the original Schwann cell tube (Fig. 2C).

Comparison of Figure 2, $A$ and $C$, showed that the terminal arbor at this endplate site was very similar before and after reinnervation. In both cases the axon entered the endplate from the left and bifurcated before occupying the synaptic sites. Almost all of the endplate regions originally occupied were reoccupied after reinnervation. In all the endplates we followed in this way, the nerve terminal branching was similar before and after reinnervation (Fig. 3; see also Fig. 11). Even when the branching was slightly different, it appeared that the previous sites were accurately reoccupied. This was because most of the differences in branching were due to new interconnections between the synaptic regions (e.g., endplate 4 in Fig. 3). Occasionally, differences in the branching pattern of the nerve were great enough that it appeared that the endplate had not been reoccupied very precisely. However, when we also stained the postsynaptic sites we could see that even in thesc endplates, reoccupation of original sites was the rule. For example, Figure 4 shows an endplate viewed before and $7 \mathrm{~d}$ after nerve crush ( 3 $\mathrm{d}$ after reinnervation) with reoccupation of the same sites but via different routes. Both the nerve terminal and the postsynaptic receptors were viewed each time to allow us to determine the precision with which the nerve reoccupied the original postsynaptic sites. The receptor distribution was unchanged, although slight atrophy in the muscle fiber had caused compression in the lateral dimension. Examining the superimposition of nerve terminal staining over receptor regions (bottom panels) showed that the reinnervating nerve occupied all of the original synaptic sites. Comparison of the nerve terminal staining before and after reinnervation, however, indicated that the way in which the nerve branched to occupy these sites was different. For example, the arrow in the left top and bottom panels points to a connecting branch betwecn synaptic sites (nerve terminations overlying receptors) present initially but absent at the reinnervated junction. The reinnervating axon (right panels) still occupied the same receptor sites but has done so without having such an interconnection. From these studies we conclude that the precision of reoccupation is related to a very local signal at the actual sites of synaptic contact (the receptor-rich postsynaptic domains and overlying synaptic basal lamina) rather than the pathway to and between the sites of synaptic contact.

\section{Sprout regression following reinnervation}

During the second week of reinnervation there was a high incidence of sprouts that were not present before nerve crush emanating from most of the nerve terminals (Figs. 2, 3). Most of these sprouts end blindly on or between muscle fibers, although some contact endplate sites (see below). Over the next 


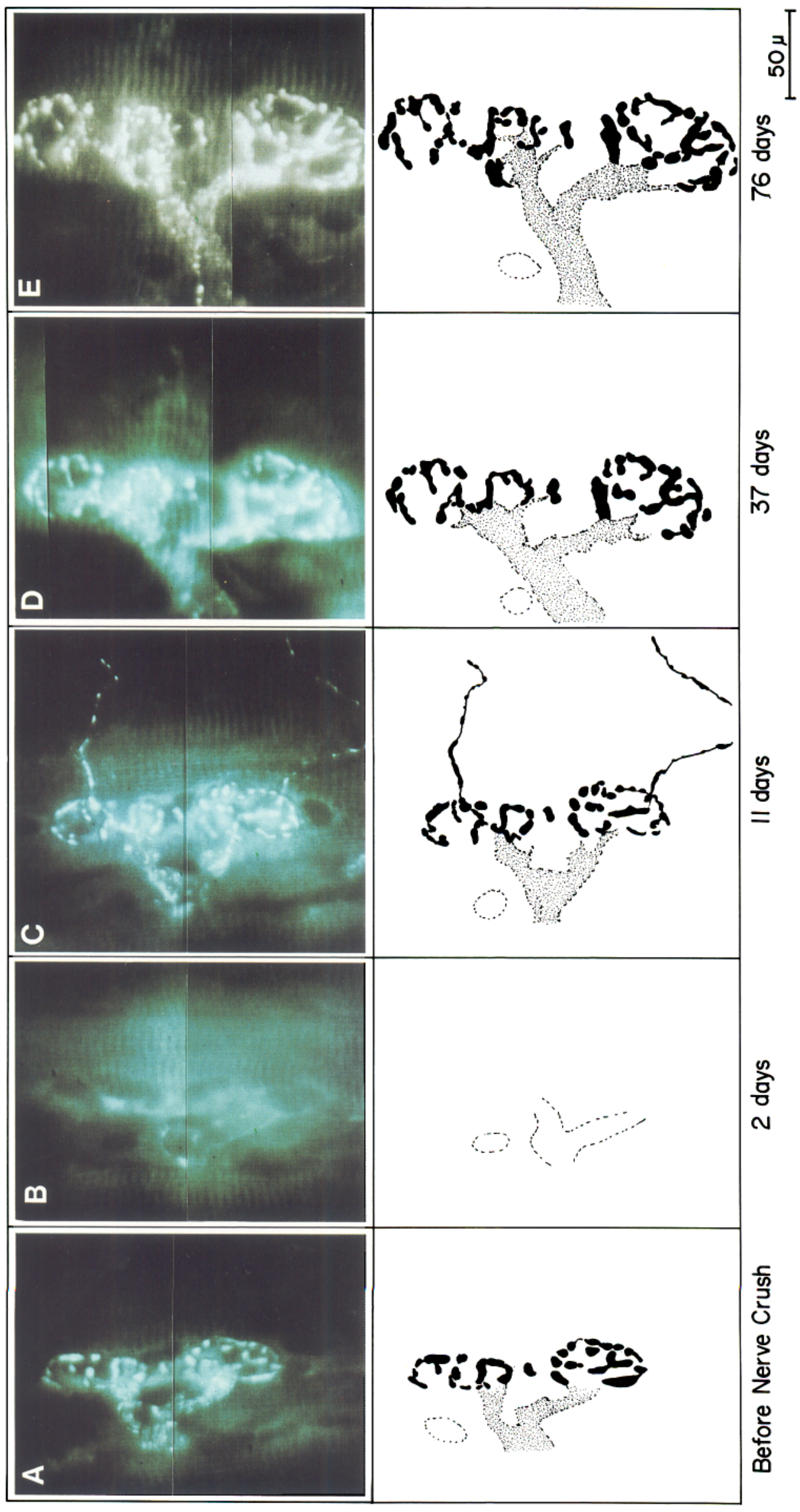

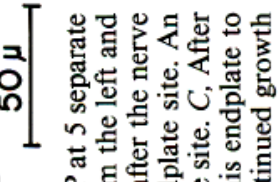

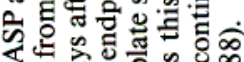

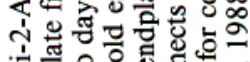

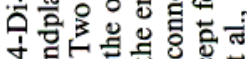

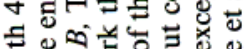

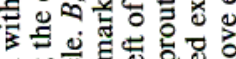

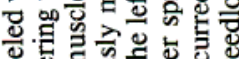

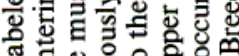
녕웅잉

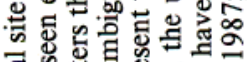

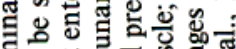

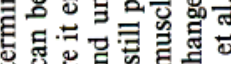

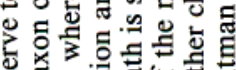
要

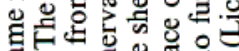

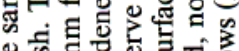
局的 용 总论

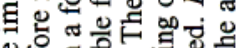

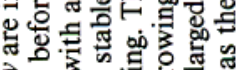

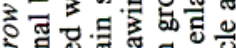
今. o

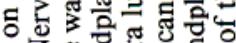

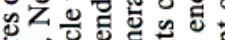

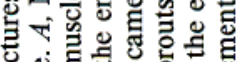
를

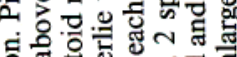

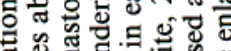

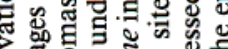

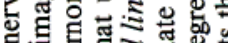
.․ㅡㄹ ए on

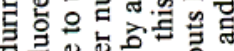

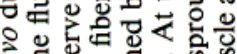
告造

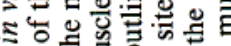
赵品

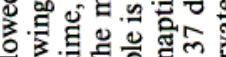

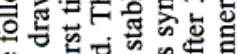

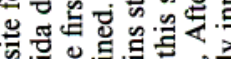

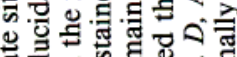
영 的㲅产 불 跑

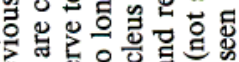

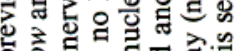

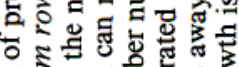

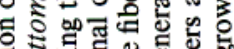
용료

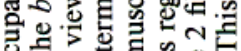
记

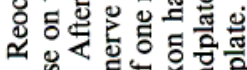
on

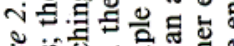

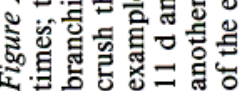


Figure 3. Typical examples of endplate sites precisely reoccupied by reinnervating axons in the sternomastoid muscle. Panels $1-4$ show a nerve terminal at individual endplate sites viewed before and $12 \mathrm{~d}$ after nerve crush. In each case, the nerve terminal has come to occupy almost all the previous synaptic sites. In examples $1-3$, the nerve branching pattern is very similar before and after nerve crush and the appearance of the nerve terminal is unchanged after reinnervation. In example 4, a connecting branch (long arrow) present prior to denervation is no longer present after reinnervation. In this endplate, several other nerve terminal branches are also different in appearance after reinnervation. Nonetheless, even in this endplate, most of the original synaptic sites appear to be reoccupied by nerve terminals. In all 4 examples, sprouts are present at the second view (short arrows) that were not seen prior to denervation. Such sprouts regress over the following weeks (see text). In the first endplate, the axon enters from the upper right at each time. In endplates 2-4 the axon enters from the lower right. Scale bar, $25 \mu \mathrm{m}$.

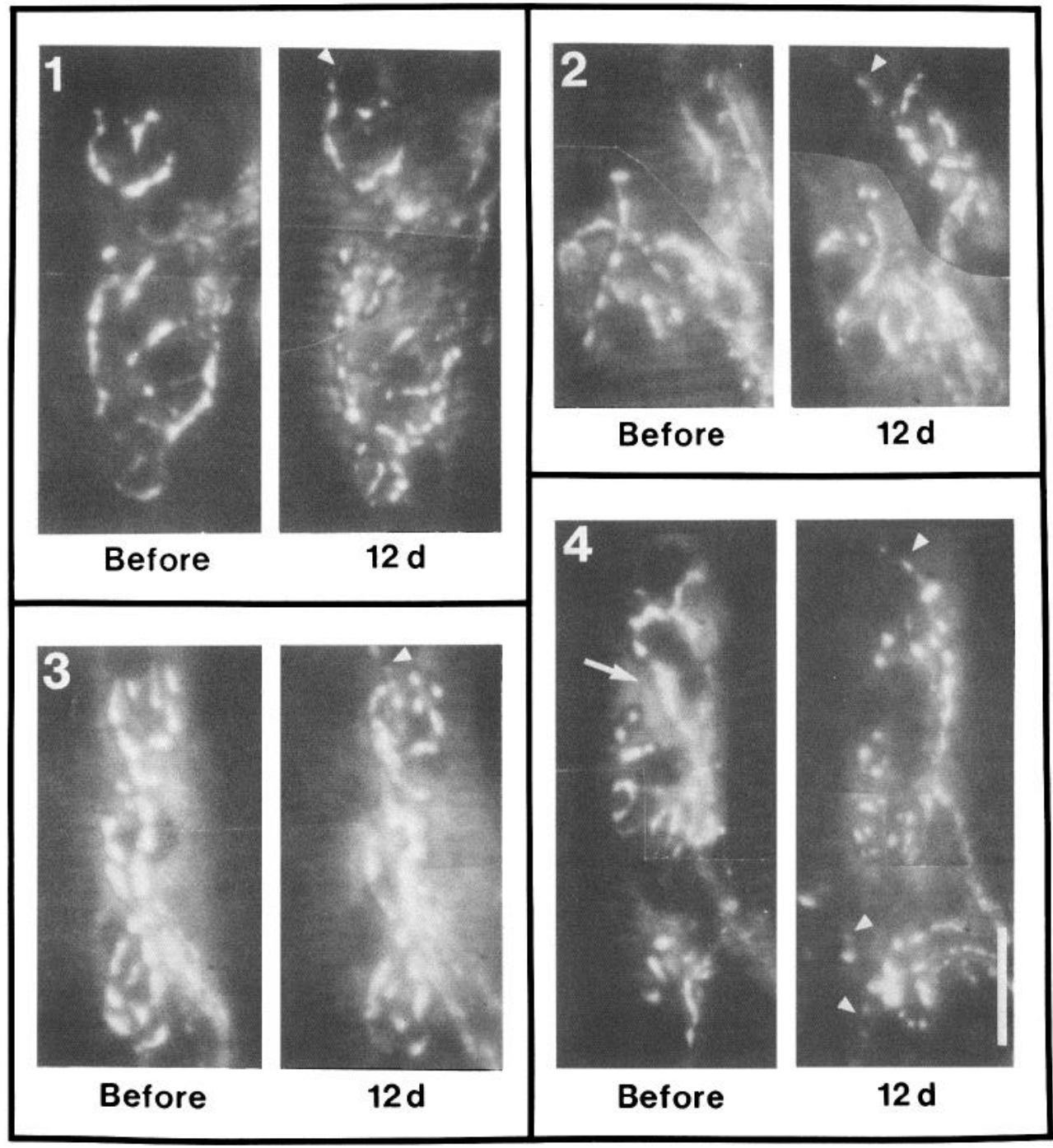

few weeks, virtually all the sprouts permanently disappeared (compare Fig. 2, $C$ and $D$ ).

The transiently appearing sprouts may be functionally significant because they sometimes terminated within endplates. Because endplates interconnected by sprouts are usually also innervated by axons growing up the old Schwann cell tubes, the sprout is likely to be the source of additional innervation to one of the endplates (the other endplate is the source of the sprout).

Just as the incidence of multiple innervation after reinnervation varied with the method of denervation, the abundance of sprouts (including endplate to endplate sprouts) also depended on the type of denervation. Following single nerve crush, sprouts were less common than following double nerve crush or nerve cut (see below).

\section{Anatomical evidence of transient multiple innervation of individual endplates during reinnervation}

Although 4-Di-2-ASP stains endplate to endplate sprouts very clearly, endplates might also be multiply innervated in other less obvious ways. In order to determine whether endplates are multiply innervated by other routes, sternomastoid muscles were stained using a combined silver/cholinesterase stain.

Examination of silver-stained muscle revealed at least 3 ways in which muscle fibers were multiply innervated. From an examination of 16 multiply innervated endplates from 3 silverstained muscles obtained $9 \mathrm{~d}$ following double nerve crush, we found 6 that were connected by endplate-to-endplate sprouts. The same number $(6 / 16)$ appeared multiply innervated by 2 axons traveling up the same nerve sheath (but see below). This is the most prevalent form of multiple innervation seen in development (Riley, 1977; O'Brien et al., 1978). The third way in which endplates were multiply innervated was by a new sprout from the nerve that entered the endplate from a different direction than the axon coming up the old nerve sheath. This last form of multiple innervation was unusual because such sprouts often meandered long distances before contacting an endplate site. In no case did we see muscle fibers multiply innervated by 2 axons at different locations along the length of the muscle fiber. As mentioned above, the only site that we saw innervated by returning axons was the original endplate site. Thus, regardless of the routes taken by the axons, most of the multiple innervation occurs within the confines of the endplate site present prior to denervation.

Anatomical signs of the incidence of multiple innervation began to decline within 2 weeks of reinnervation, in parallel with the physiological evidence (already discussed). Using 


\section{Nerve}

\section{AChR}

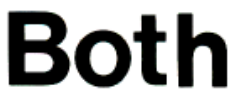

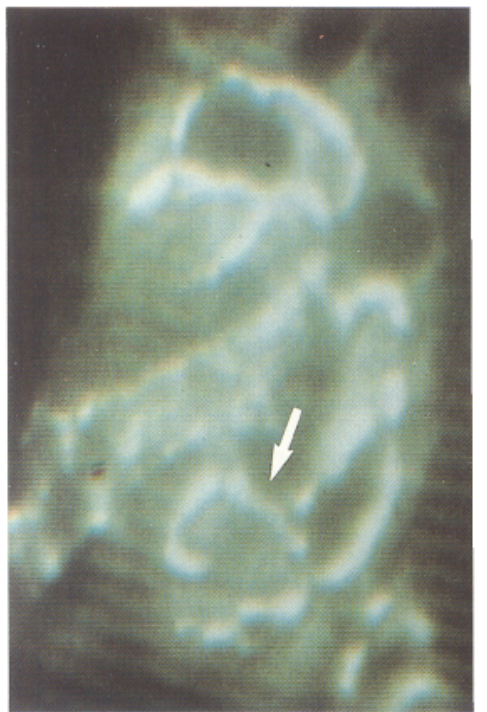
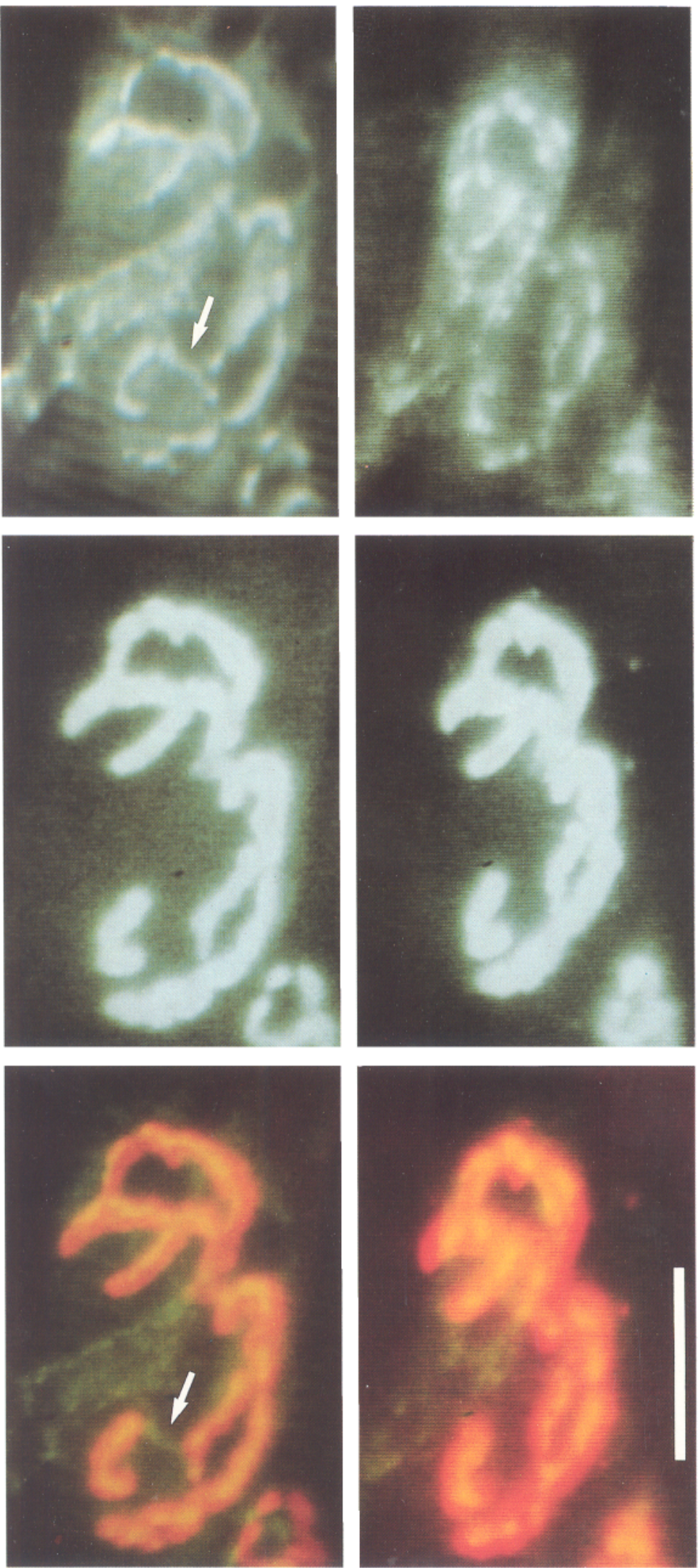

Before

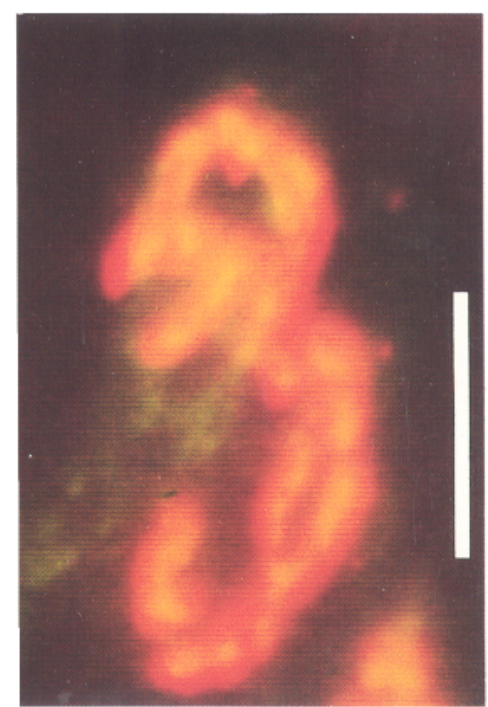

7 days
Figure 4. Precise reoccupation of $\mathrm{ACh}$ receptor-rich regions by a nerve with a different branching pattern than that of the nerve present originally. Nerve terminal and $\mathrm{ACh}$ receptor distribution of an individual endplate viewed before and $7 \mathrm{~d}$ after nerve crush $(3 \mathrm{~d}$ after return of the axons to the muscle). The top row of pictures shows the nerve terminal branching pattern stained with 4-Di-2-ASP before and shortly after reinnervation. At each time, the axon enters the endplate from the lower left. The nerve terminal present after reinnervation branches differently in the lower portion of the endplate (see $a r$ row). The second row of pictures shows the postsynaptic $\mathrm{ACh}$ receptor distribution stained with rhodaminated $\alpha$-bungarotoxin before and after reinnervation. Although the muscle fiber has atrophied somewhat by the second view (causing the endplate to appear to shrink in the lateral dimension), the receptor distribution before and after reinnervation is the same. The bottom row of pictures shows the nerve terminal image superimposed on the receptor distribution at each time. The nerve terminal is yellow and the ACh receptor distribution is red. At both times (before and after reinnervation), the nerve terminal precisely occupies all receptor regions. Scale bar, $50 \mu \mathrm{m}$. 
Figure 5. Synaptic boutons are eliminated at the time sprouts regress. $A$, Two endplates ( 1 and 2 ), each innervated by an axon growing up and old Schwann cell tubes (not shown), are also interconnected by a sprout. This image was obtained $9 \mathrm{~d}$ after a nerve crush, which is approximately $5 \mathrm{~d}$ after the axons have regrown to the muscle. $B$, Eight days later, the sprout between the 2 endplates is no longer present. $C$, Higher-magnification view of endplate 1 (box in $A)$ at the time the sprout is present. Note the brightly staining boutons just above the sprout. $D$, Highermagnification view of endplate 1 ( $b o x$ in $B$ ) at the time the sprout has regressed. The nerve terminal staining initially present above the former sprout has disappeared. Scale bar: $A$ and $B, 50$ $\mu \mathrm{m} ; C$ and $D, 25 \mu \mathrm{m}$.

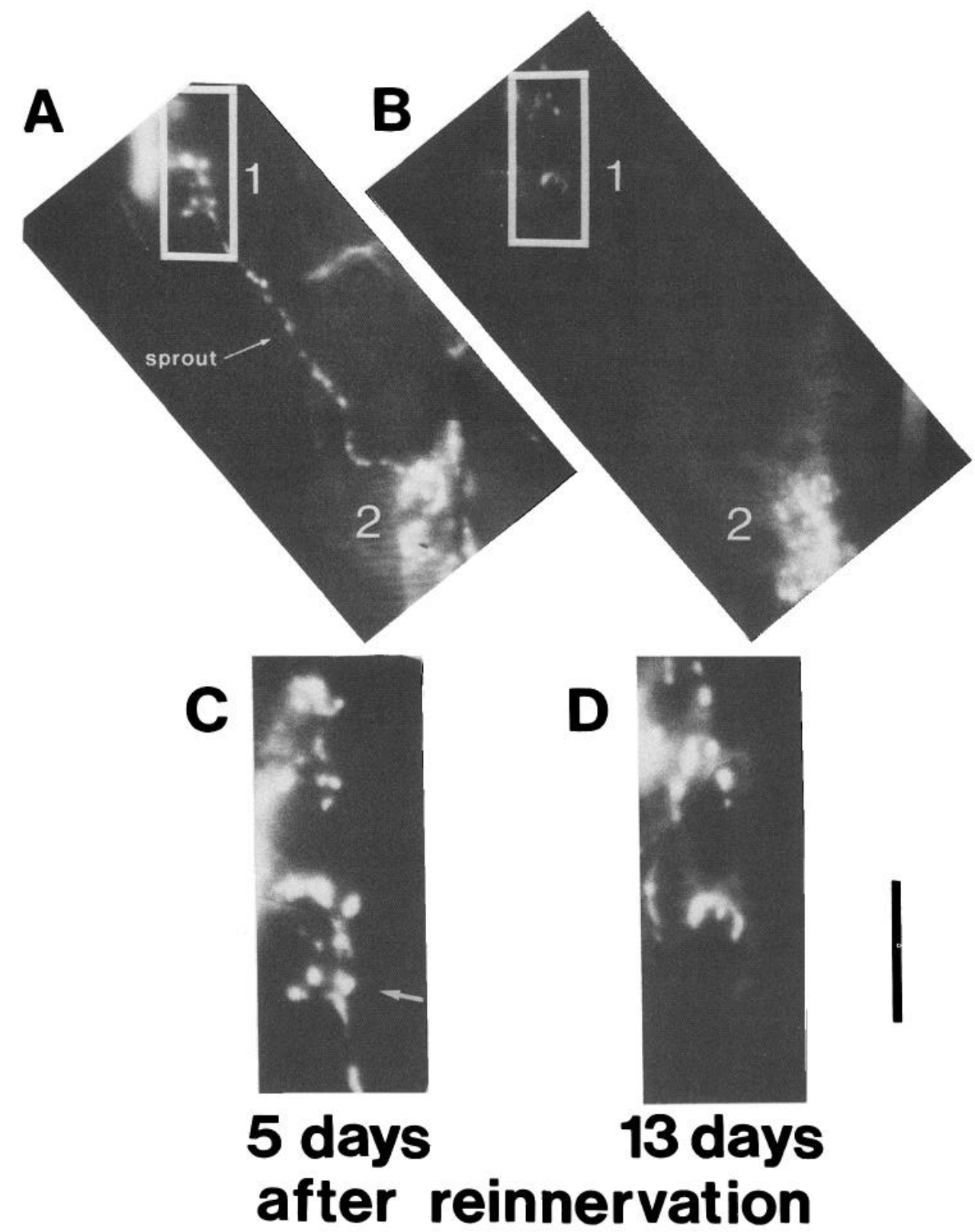

4-Di-2-ASP, the peak number of endplate-to-endplate sprouts occurred $9 \mathrm{~d}$ after single nerve crush (Fig. 1). At $9 \mathrm{~d}$, we estimate $20 \%$ of the endplates were multiply innervated by an endplateto-endplate sprout (30/150). By 35 d after nerve crush, however, only $3 \%$ of the endplates appeared multiply innervated by this route $(3 / 110)$. Anatomical measures of multiple innervation increased when the nerve was recrushed $4 \mathrm{~d}$ after the first crush to delay the return of the axons, consistent with the physiological evidence already mentioned. Nine days after the second of 2 nerve crushes, we estimate $37 \%(n=28 / 75)$ of the endplates were multiply innervated by endplate-to-endplate sprouts. A month later, this value had declined to $9 \%(7 / 75)$. Despite the difference in the peak level of multiple innervation seen following single-versus double-crush lesions of the nerve, in both cases sprouts were eliminated until very few endplates were interconnected by sprouts. Silver/cholinesterase staining of the sternomastoid after reinnervation confirmed the vital dye results:
$3 \frac{1}{2}$ weeks following double nerve crush, there was very little evidence of multiple innervation by endplate-to-endplate sprouts or by new branches from the nerve. Multiple axons traveling up the Schwann cell tube were still occasionally seen. In some of these cases, it was clear that these were branches of the same axon that had bifurcated long before reaching the endplate site. This branching was not seen in normal muscle.

\section{Bouton loss associated with sprout regression}

Although the elimination of sprouts transiently projecting to endplate sites might be an indication of synapse elimination, it is possible that the sprout had not made a synaptic contact. To determine if sprouts had made such contacts, endplates were viewed that appeared to be multiply innervated by a sprout both before and after the loss of the sprout. By viewing such endplate sites we found several $(4 / 10)$ in which we could clearly see that the elimination of the sprout was coupled with the loss of bou- 
tons at the endplate site (Fig. 5). In each case the eliminated boutons were located in the region of the endplate where it appeared the sprout had entered. The boutons lost were anatomically indistinguishable from the synaptic contacts that remained. Moreover, the loss of boutons was coincident with the decrease in functional measures of multiple innervation. This suggests that the loss of these sprouts is, at least in part, responsible for the synapse elimination occurring in this muscle.

That we could find endplates in which boutons had been eliminated was surprising. One might have expected that the axon remaining following synapse elimination would either cooccupy or rapidly reoccupy the sites vacated by the eliminated axon, making synapse elimination impossible to detect anatomically. However, as mentioned above, 4 out of 10 endplates that were contacted by endplate-to-endplate sprouts showed bouton loss at the time sprout regression occurred. The incidence of endplates that lost boutons $(40 \%)$ is close to the expected incidence of $50 \%$ (because only half the endplates were recipients of sprouts, the remainder being the source; but see Materials and Methods for further discussion). The ability to view bouton loss suggests that once synapse elimination has caused loss of boutons from synaptic sites, the sites are not rapidly reoccupied by the remaining axon. Thus, although axons precisely reoccupy the old synaptic site, some of their synaptic endings can subsequently be eliminated.

\section{Nerve terminals and $A C h$ receptors do not change at normal endplates viewed at multiple times}

Because nerve terminals vacated previous postsynaptic sites during reinnervation, we wished to see what happened to those sites over time. In order to do that we viewed the pre- and postsynaptic sites by additionally staining with fluorescently tagged $\alpha$-bungarotoxin to label the ACh receptors. We first determined if postsynaptic receptor sites of endplates could be repetitively viewed without affecting endplate morphology (preor postsynaptically). Nerve terminals alone have been viewed at multiple time points without obvious effect on morphology (Balice-Gordon and Lichtman, 1987; Lichtman et al., 1987). In 13 muscles in which the same pre- and postsynaptic regions were viewed twice $2 \frac{1}{2}$ weeks apart (the interval used for many of the studies in this paper), we found virtually no changes occurred in endplate morphology (Fig. 6). In $98 \%(62 / 63)$ of the endplates followed, the nerve terminal and postsynaptic receptor distributions were identical at the second viewing. The one endplate that did appear to change lost a small branch less than $10 \%$ of the total length $(8 \mu \mathrm{m})$. For our studies of reinnervation, we only counted endplates as changed when more than $10 \%$ of length (10-15 $\mu \mathrm{m}$, on average) was lost or added.

\section{Postsynaptic receptor sites are lost after reinnervation}

To view ACh receptor distributions at endplates, muscles were stained with rhodaminated $\alpha$-bungarotoxin. Approximately 5 superficial endplates were photographed at $625 \times$ in each of 16 anesthetized mice and a map of their locations was drawn. The nerve to the sternomastoid was then crushed with a forceps, the wound sutured, and the animals allowed to recover. Seventeen to $22 \mathrm{~d}$ later, the animals were reanesthetized and the same endplate sites relocated by applying new rhodaminated bungarotoxin. At this interval, the nerve has completely reinnervated the muscle and the period of transient multiple innervation of fibers is essentially over (see Fig. 1). Seventy-one percent of endplates were nearly identical on second viewing: in each
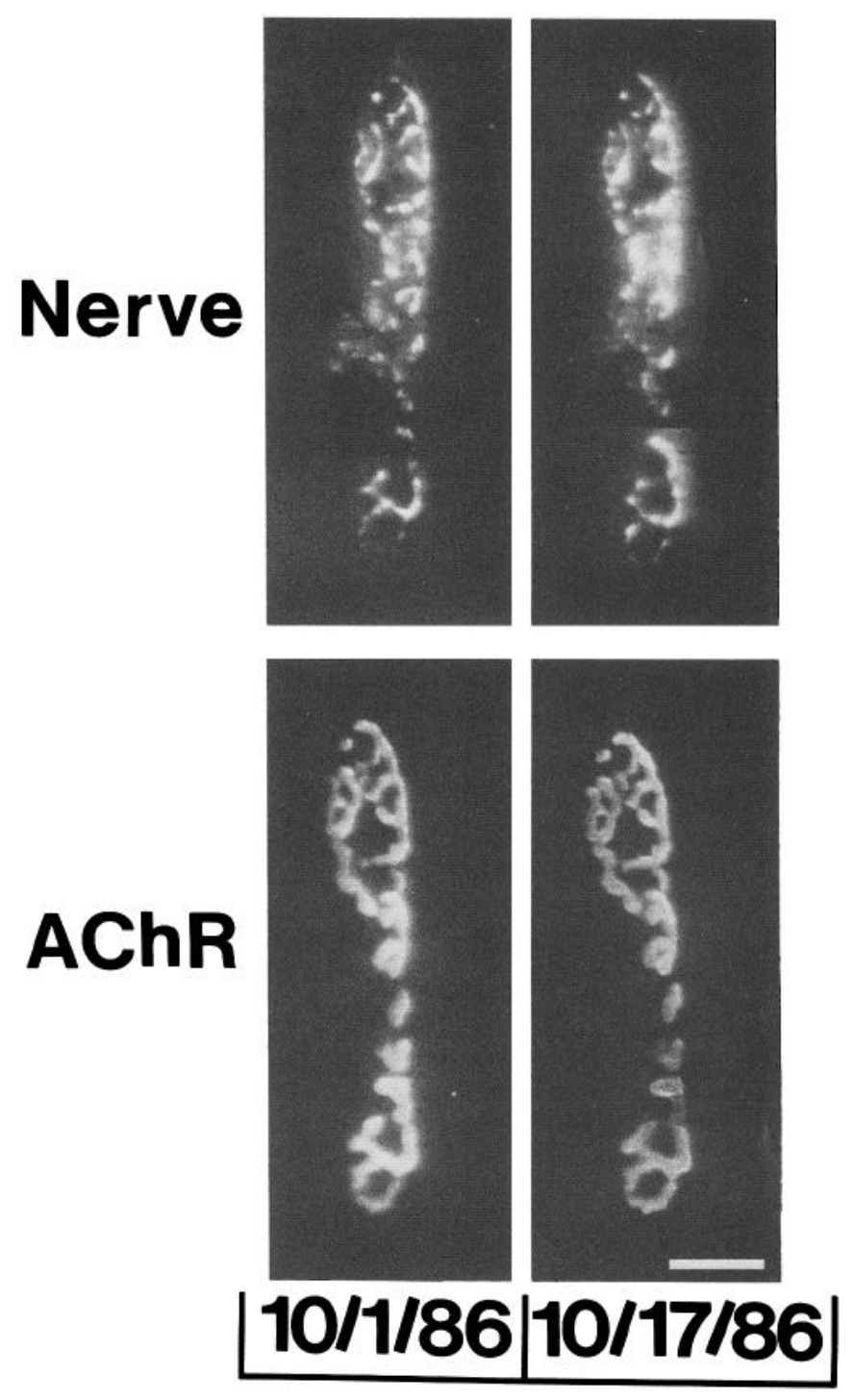

Figure 6. Endplates in the sternomastoid muscle of mice do not change when the pre- and postsynaptic elements are viewed repeatedly in normal animals. Nerve terminal and ACh receptor distribution of an individual endplate in vivo viewed once and again $16 \mathrm{~d}$ later. The top panels show the nerve terminal stained with 4-Di-2-ASP at each time. The axon enters from the left in the middle of the nerve terminal. The bottom panels show the ACh receptors stained with rhodaminated $\alpha$-bungarotoxin at each time. There is precise alignment between nerve terminal and receptor sites. No changes in either nerve terminal or ACh receptor distribution are seen. Scale bar, $25 \mu \mathrm{m}$.

case, all of the original receptor regions were still present and there were no new receptor patches. Fifteen out of 51 endplates (29\%) that were followed, however, had lost more than $10 \%$ of their receptor regions by their second viewing (Fig. 7). Endplate regions that were present initially (typically an entire branch or a cluster of nearby branch parts) were no longer visible or were extremely faint with new rhodaminated bungarotoxin staining. In a few of these changed endplates, almost half of the original postsynaptic area could no longer be stained, whereas areas still present were entirely unchanged. Thus, in every one of the endplates that were noticeably different in appearance at the second viewing, postsynaptic regions were lost. Two of the endplates viewed had small $(5 \mu \mathrm{m})$ new regions of $\mathrm{ACh}$ receptors present at the second time. 

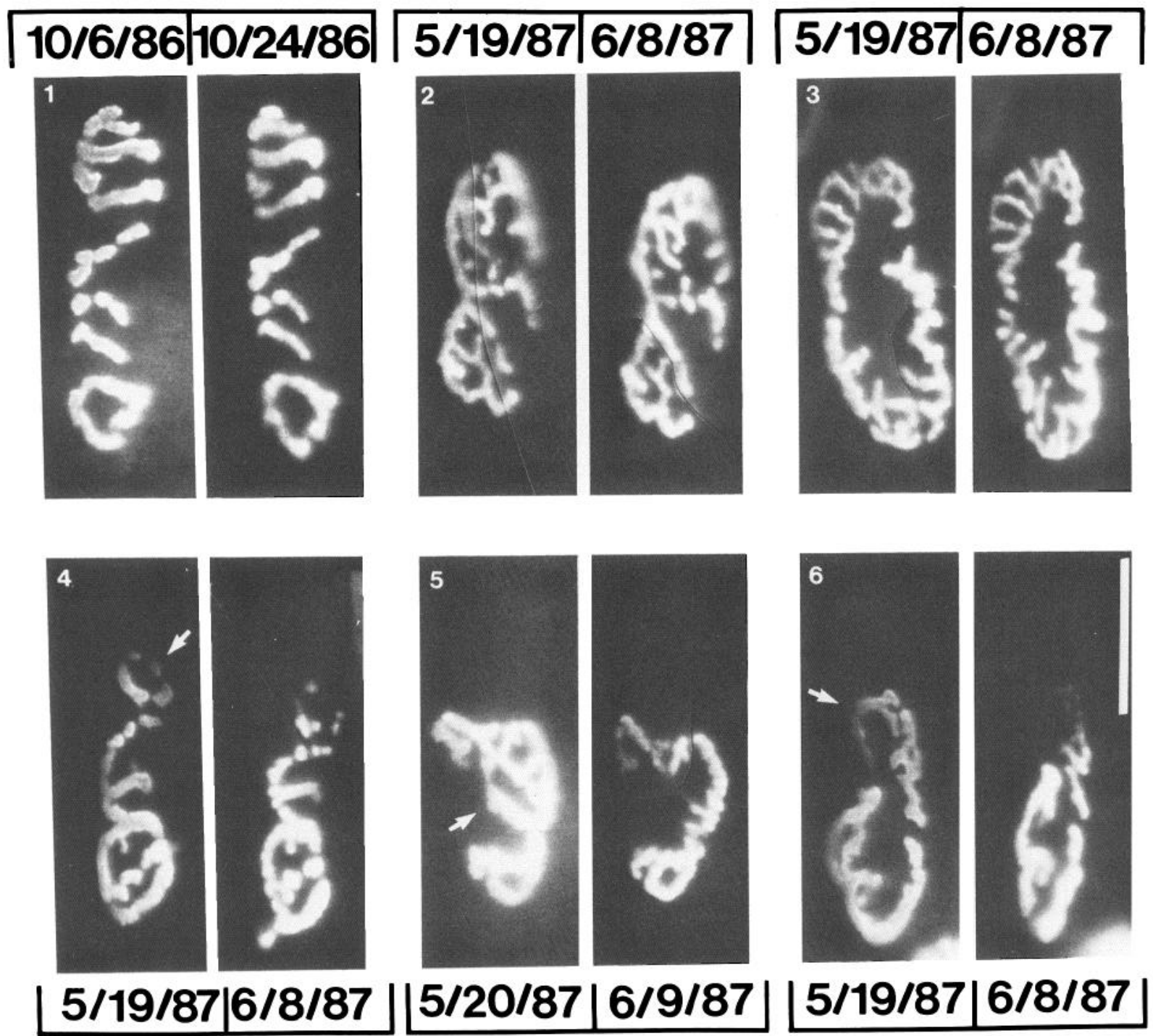

Figure 7. Approximately one-third of endplates lose ACh receptors from some sites after brief denervation following a single nerve crush lesion. ACh receptor distribution of endplates in vivo viewed before and 18-20 d after nerve crush and subsequent reinnervation. Representative examples of endplates studied are shown in panels $1-6$. The left image in each pair shows the receptor distribution prior to nerve crush and the right image shows after reinnervation. Arrows point to receptor areas eliminated at the second viewing. The dates at which each endplate was viewed are indicated. Panels 1-3 show endplates that did not change at all; panel 4 shows an endplate that lost less than $10 \%$ of its receptor area. The endplate shown in panel 4 is one of the 2 endplates that had a small new area of receptors at the second view. The addition is present at the bottom of the endplate. Panels 5 and 6 show endplates that lost more than $10 \%$ of their receptor area. In a few cases, the former sites are still visible due to the presence of some very faint staining. Usually, however, the receptors are eliminated to imperceptible levels. Scale bar, $50 \mu \mathrm{m}$.

The receptor distribution at individual endplates was also viewed before and at various times after the nerve had been crushed twice, which delayed axonal return by $3-4 \mathrm{~d}$ (see Section 1). The endplates were re-viewed 17-22 d after the second crush (21-26 d after initial viewing) by reapplying rhodaminated bungarotoxin. In these animals, only $27 \%(16 / 59)$ were unchanged, the other $73 \%$ having significant deletions of receptor areas at the second time (Fig. 8). There were no additions of receptor sites to any of these endplates. Thus, approximately twice as many endplates lost $\mathrm{ACh}$ receptor patches following double, as compared with single, nerve crush.

Following nerve cut, which delays axonal return most severely, the receptor loss at individual endplate sites was dramatic. Not only had $100 \%$ of the endplates that could be definitely relocated ( $n=10$; Fig. 9) lost receptor sites, but in many cases the endplates were difficult to relocate because they had changed so dramatically. 4-Di-2-ASP staining was used to show that the endplates that had changed had been reinnervated.

\section{Endplates in permanently denervated muscles do not lose receptor areas}

One possible explanation for the changes in ACh receptor distribution is that denervation itself causes loss of receptor-dense regions. To test this idea, we permanently denervated several muscles (see Materials and Methods) and then relocated the same 11 endplates on 5 separate occasions during the subsequent $45 \mathrm{~d}$ (Fig. 10). Permanent denervation caused progressive muscle atrophy in which muscle fibers shrank in the lateral dimension. This shrinkage obscured details of the receptor distribution, especially in the lateral dimension at intervals greater than 2 weeks. Nonetheless, for several reasons it did not seem that any receptor regions had been lost. First, even very small spots 


\section{$5 / 21 / 87|6 / 13 / 87| 5 / 21 / 87 \mid 6 / 1 3 / 8 7 \longdiv { 5 / 2 1 / 8 7 | 6 / 1 3 / 8 7 }$}
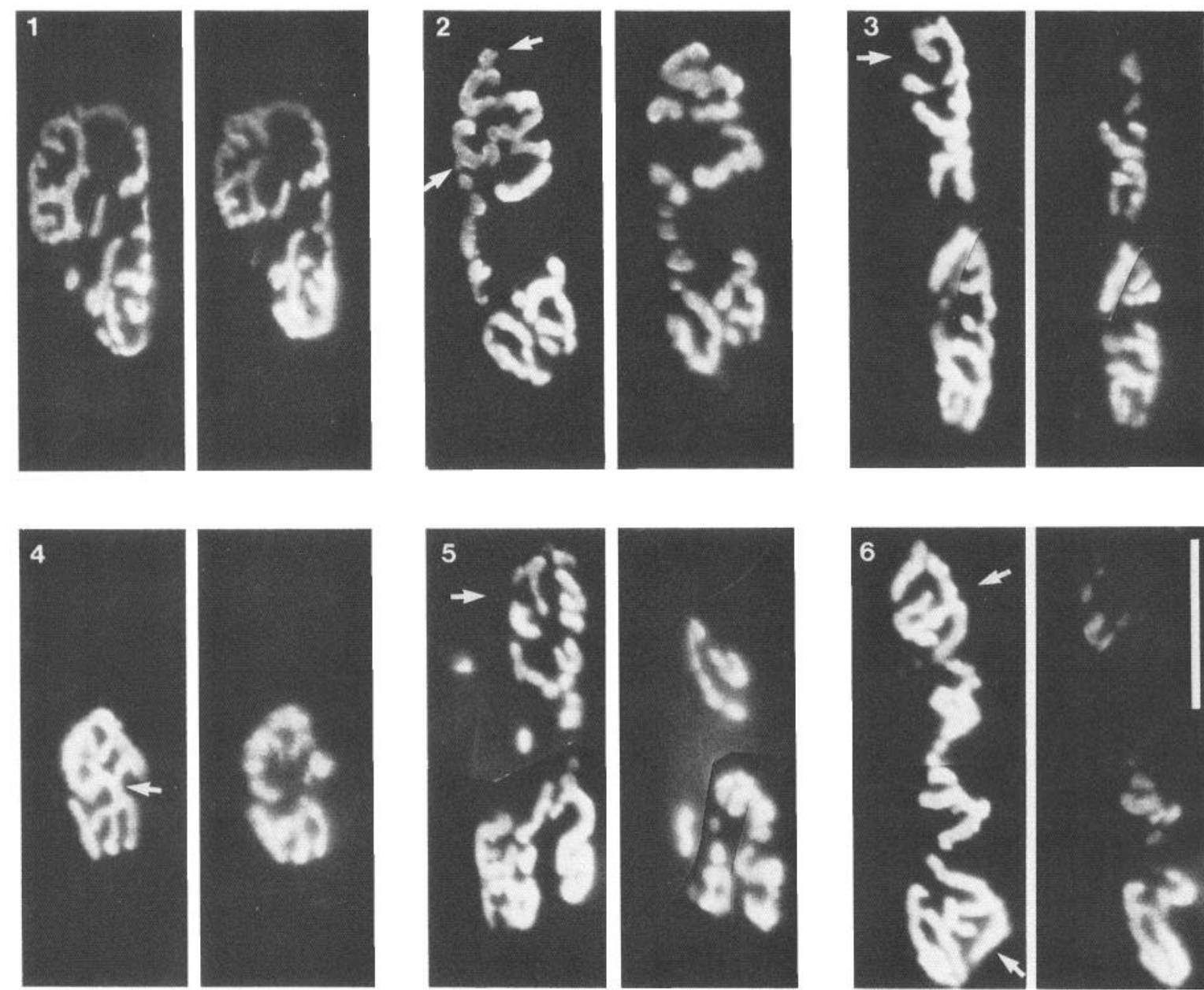

\section{$5 / 21 / 87 \mid 6 / 13 / 87$}
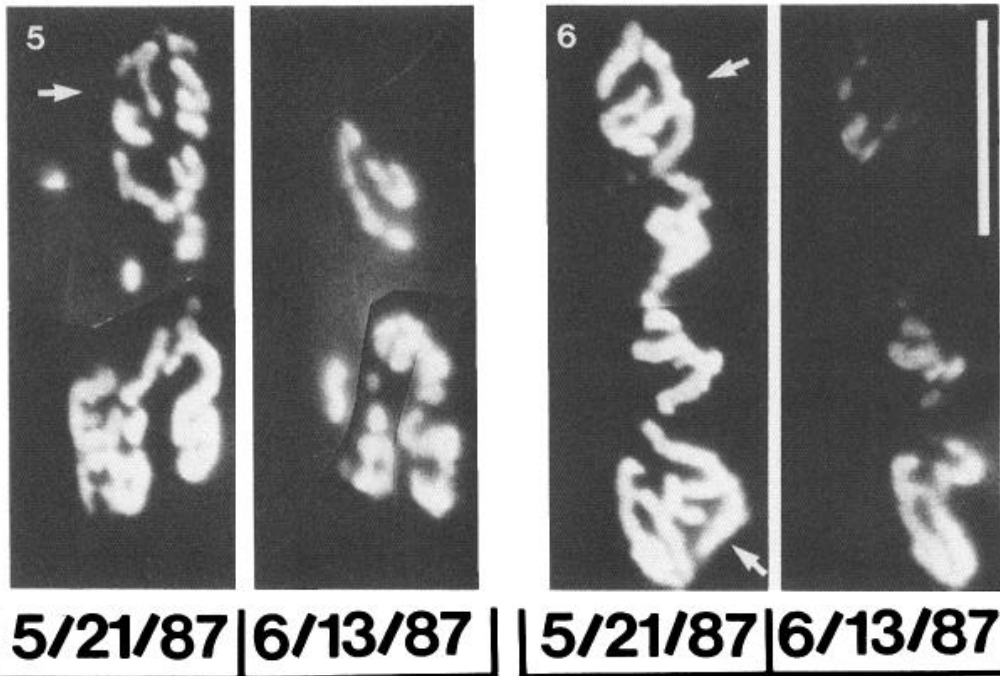

\section{$5 / 21 / 87 \mid 6 / 13 / 87$}

Figure 8. Almost three-quarters of endplates lose ACh receptor sites after delayed reinnervation following a double nerve crush. ACh receptor distribution of endplates in vivo viewed before and after the second nerve crush (see Materials and Methods) and subsequent reinnervation. Representative examples of endplates studied (panels 1-6). The left panel of each pair shows the receptors prior to the first nerve crush, and the right panel shows the receptors $19 \mathrm{~d}$ after the second of 2 nerve crushes. Arrows point to receptor areas that are eliminated by the time the second view was obtained. The dates at which each endplate was viewed are indicated. Panel $I$ shows an endplate that did not lose receptor areas following a double nerve crush; panels $2-6$ show endplates that lost more than $10 \%$ of their receptor area. Scale bar, $50 \mu \mathrm{m}$.

that were in isolation were always definable throughout the intervals studies (for example, see arrow in Fig. 10). Second, the length of each endplate from one end to the other did not change. Thus, no regions at the top or bottom of these endplates had been eliminated, even though such loss was often seen during reinnervation (see, for example, Fig. 8, endplate 5). Finally, at the shorter intervals no signs of faintly staining receptors were seen, even though in reinnervation this is common before sites , are lost (see Section 11 below). Thus, denervation itself does not appear to cause the loss of receptor-rich areas at endplates. Rather, the nerve must be present for the changes to occur.

\section{Nerve terminals and receptors are lost from the same regions}

To determine whether the loss of receptors was related to the loss of nerve terminals we had observed during reinnervation
(Section 6), we viewed the nerve terminal and receptor distribution of individual endplates before and after the reinnervation process. Prior to nerve crush, there was an impressive alignment of receptor-rich areas and nerve terminals (see, for example, Fig. 6). In normal animals viewed before nerve crush we found no instances $(n=77)$ in which stained postsynaptic regions were unoccupied by nerve or stained nerve terminals were overlying receptor-free regions. When nerve terminals and receptor areas were viewed a second time, $42 \mathrm{~d}$ after double nerve crush, we found, as before (Section 8), 70\% (14/20) of the endplates were missing postsynaptic regions that were present before nerve crush. When the overlying nerve terminals were stained, the nerve terminals also showed deletions, and these were at exactly the sites from which postsynaptic receptors were lacking (Fig. 11). Thus, both the endplates that lost postsynaptic regions and the endplates that remained unchanged had a perfect alignment of 


\section{Od}
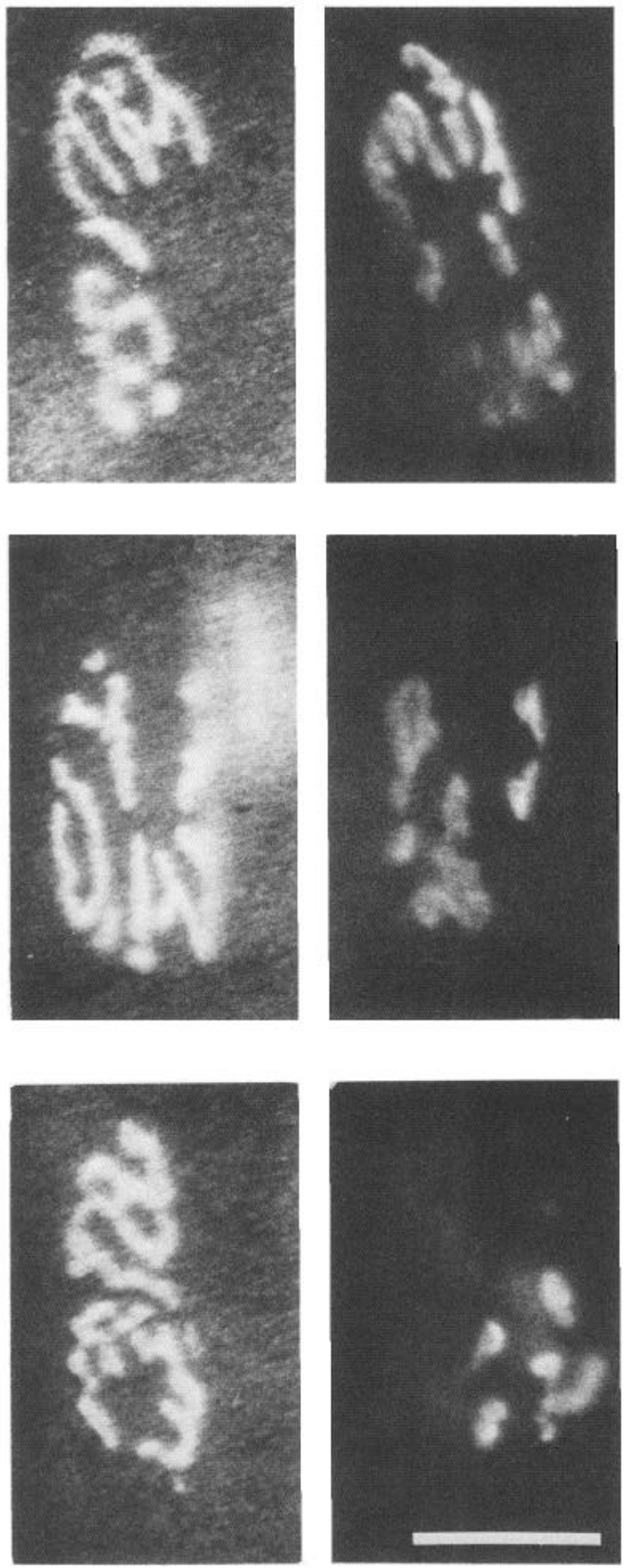

Figure 9. All endplates lose $\mathrm{ACh}$ receptor sites after reinnervation following prolonged denervation due to nerve cut. ACh receptor distribution of 3 endplates in vivo viewed before and after nerve cut and subsequent reinnervation. The left panel of each pair shows the receptors prior to nerve cut, and the right panel shows the receptors $46 \mathrm{~d}$ following nerve cut. Every endplate has lost many receptor sites. Many endplates are so changed that reidentification is difficult. Scale bar, $50 \mu \mathrm{m}$.

postsynaptic receptors and overlying nerve terminals. This association between loss of receptors and loss of nerve terminals was also true for all our other experiments that induced receptor loss. Thus, following single and double nerve crush and nerve cut, areas of endplates that had lost receptors always showed loss of nerve terminals as well as when stained with 4-Di-2ASP.
This loss of receptors and nerve terminals correlates with the loss of multiple innervation. The anatomical measures of endplates receiving more than one input and the physiological measure of multiple innervation parallel the percentage of endplates losing synaptic sites. Following single nerve crush, the incidence of multiple innervation (anatomically, 19\%; physiologically, $9.5 \%)$ and the incidence of loss of synaptic sites $(29 \%)$ are low compared with these values at endplates reinnervated following double nerve crush $(37,22$, and $70 \%$, respectively). After nerve cut the physiological measure of multiple innervation was greatest (up to $56 \%$ ) and all the endplates appeared to have lost synaptic sites. This correlation between the incidence of multiple innervation and the degree of synaptic loss in these experimental settings suggests that synapse elimination is the cause of the loss of synaptic sites. The fact that the anatomical and physiological measures of multiple innervation are less than the incidence of synapse loss should not be taken to mean that there is necessarily another cause for synapse loss besides the loss of multiple innervation. Our measures of multiple innervation only sample the number of multiply innervated endplates at a given time. On the other hand, loss of synaptic sites is a cumulative measure that is likely to be much greater.

\section{ACh receptbr loss occurs shortly after reinnervation}

To see when postsynaptic regions were lost, individual endplates were viewed before and once again at various times following reinnervation. Five days after the second of 2 nerve crushes (the axons have been back in the muscle approximately 1-2 d) none of the endplate sites we viewed twice $(n=13)$ showed any change in the pattern of $\alpha$-bungarotoxin binding compared with the distribution before nerve crush (Fig. 12). During the next $2 \mathrm{~d}$, nearly complete axonal reoccupation occurs, but there was still no evidence of any change in receptor distribution $(n=24)$.

By 8-11 d after the second nerve crush the first signs of change in postsynaptic receptor distribution were evident. Regions of some endplates $(44 \% ; n=86)$ viewed $8-11 \mathrm{~d}$ after the second crush appeared only lightly stained with rhodaminated $\alpha$-bungarotoxin (20-50\% as bright - see Materials and Methods) compared with other parts of the same endplate. Single branches of receptor staining or nearby regions of several receptor patches were spotty in appearance, less intensely stained, and often narrower than initially. By 17-23 d after the second nerve crush about $71 \%$ of the endplates $(n=29)$ have lost significant postsynaptic regions. However, at this interval very few faintly staining receptor regions are still present. This suggests that areas that are faintly staining at 8-11 d disappear entirely over the following week.

In order to determine directly if faintly staining ACh receptor areas were subsequently lost entirely, we viewed endplates multiple times during the period when receptor sites were lost. When we viewed the same endplate before nerve crush and at 8 and $18 \mathrm{~d}$ after a double nerve crush, regions initially present could be seen first to stain less intensely and then disappear (Fig. 13). This demonstrates that receptor areas disappear by a gradual decrease in the number of receptors in the area to be eliminated.

To determine how rapidly receptor sites are eliminated, we viewed muscles at different times following a double nerve crush. At each time we calculated the percentage of endplates with faint receptor sites. A receptor area was considered faint if it was $20-50 \%$ as bright as neighboring receptor areas. Areas less than $20 \%$ as bright as neighboring areas were difficult to identify positively, while areas more than $50 \%$ as bright were not clearly 


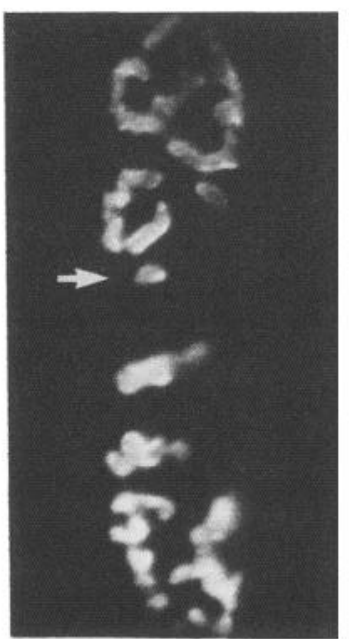

Before Nerve Cut

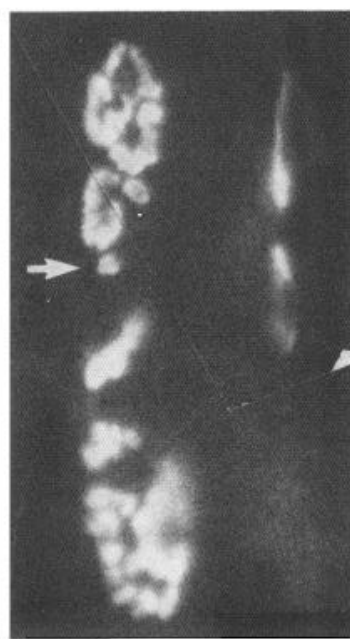

11 days

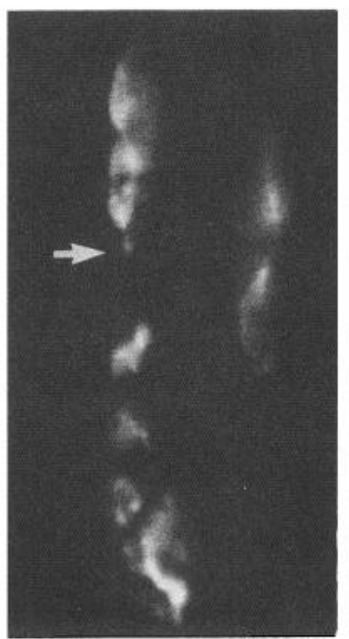

17 days
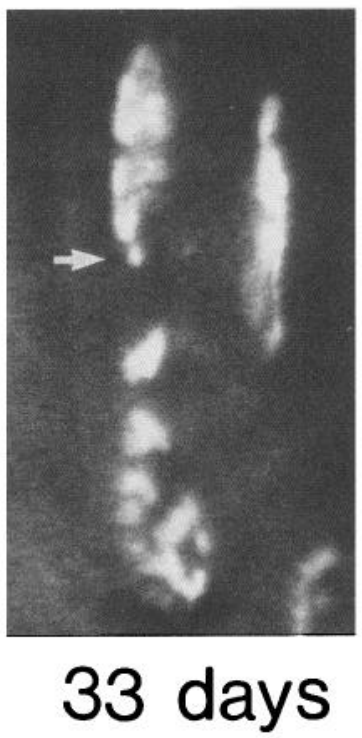

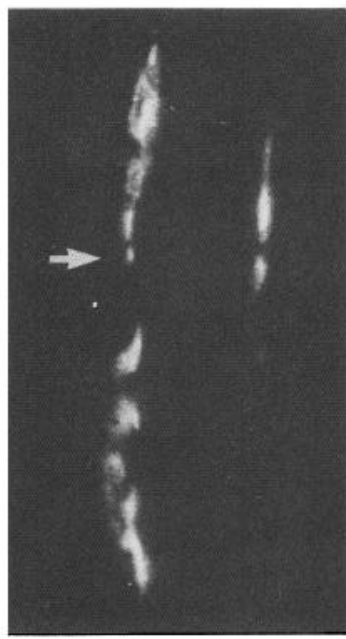

45 days

Figure 10. Endplates do not lose ACh receptor sites during permanent denervation. The ACh receptor distribution of endplates was followed in vivo during chronic denervation. The row of pictures shows an individual endplate site stained with fluorescent $\alpha$-bungarotoxin before and at approximately $10 \mathrm{~d}$ intervals over a $45 \mathrm{~d}$ period following nerve cut. Despite the shrinkage of endplates in the lateral dimension due to atrophy of denervated muscle fibers, there was no obvious loss of the receptor sites at each time (one such site is shown by the arrow). Although denervated endplates have extrajunctional receptors both diffusely (Fambrough, 1981) and in patches (Ko et al., 1977), the endplate sites remained the sites of highest receptor density due to the continual insertion of new receptors at these sites. In the 11-45 d views a second endplate can be seen to the right due to muscle atrophy. Scale bar, $25 \mu \mathrm{m}$.

faint. We looked at the percentage of endplates with faint receptor sites at each day (approximately 20 endplates at each time) from $7 \mathrm{~d}$ after completing a double nerve crush (when endplates first begin to lose sites) until $17 \mathrm{~d}$ when endplates no longer have faint regions. We found that during this $10 \mathrm{~d}$ period the percentage of endplates with faint receptor areas rapidly increased until $11 \mathrm{~d}$ (reaching a peak of $46 \%$ ), after which the percentage of endplates with faint receptor areas fell off, until at $17 \mathrm{~d}$ only $6 \%$ of the endplates had faint areas. During these $10 \mathrm{~d}$ the average percentage of endplates with faint receptor sites was $24 \%$ and a total of $70 \%$ of the endplates ultimately changed. From this we calculated that it takes approximately $3.5 \mathrm{~d}$ for a faint receptor region to be eliminated $(24 \% / 70 \% \times 10 \mathrm{~d}=3.5$ d).

It thus appears that loss of receptor sites begins $8 \mathrm{~d}$ after the last nerve crush and is complete by 17-23 d. If this were true, then endplates that have lost receptor regions early in reinnervation should remain stable after the period of elimination is over. To determine directly whether receptor loss was strictly delimited to an approximately $9 \mathrm{~d}$ period (days 8-17) after the nerve returned, we viewed 28 endplates visualized before nerve crush, 17-23 d after nerve crush, and also a third time, 35-36 $\mathrm{d}$ after the initial view. No endplate showed further significant loss (Fig. 14): regions that had been previously eliminated were still missing and no new areas were present. Thus, during the first 2 weeks of reinnervation, endplates lose postsynaptic areas but then stabilize. As late as $72 \mathrm{~d}$ after double nerve crush, endplates are still missing receptor sites present prior to denervation and there is no sign that sites are reforming. This suggests that loss of receptor sites is permanent: once lost, the sites are never reformed. Because nerve terminal loss parallels the change in receptor distribution, these endplates must also be losing nerve terminals for only a limited time during reinnervation. Thus, during the period of synapse elimination, endplates appear to lose both nerve terminals and the underlying receptors permanently, but once the competitive process is complete, no further loss of synaptic sites takes place.

Interestingly, the time at which receptors are lost is precisely when the physiological measure of multiple innervation is declining (7-15 d; see Fig. 1). This is further evidence of a causal relation between loss of synaptic sites and the elimination of multiple innervation. Anatomically, we have followed loss of multiple innervation by viewing the disappearance of sprouts that interconnect endplates (see Fig. 1). This measure of the decline in multiple innervation lags behind both the physiological measure of multiple innervation and the loss of receptor sites. One reason for this delay may be that synapse loss is followed more slowly by the loss of the sprout giving rise to the synapse. We also have evidence that the time of bouton elimination lags behind receptor loss (Section 14 below).

\section{Endplate regions are reoccupied before they are eliminated}

Some of the loss of nerve terminals and underlying receptors during reinnervation could be explained by the incomplete reoccupation of endplate sites. In partially reinnervated endplates it is possible that the innervating axon might cause elimination of unoccupied postsynaptic receptor regions by reorganizing the postsynaptic site to coincide with the location of the nerve terminal. Thus, it is important to determine whether postsynaptic regions that are eliminated are first reoccupied by an axon during reinnervation. Nerve terminals and receptor sites at endplates were viewed early in reinnervation in muscles in which the nerve 


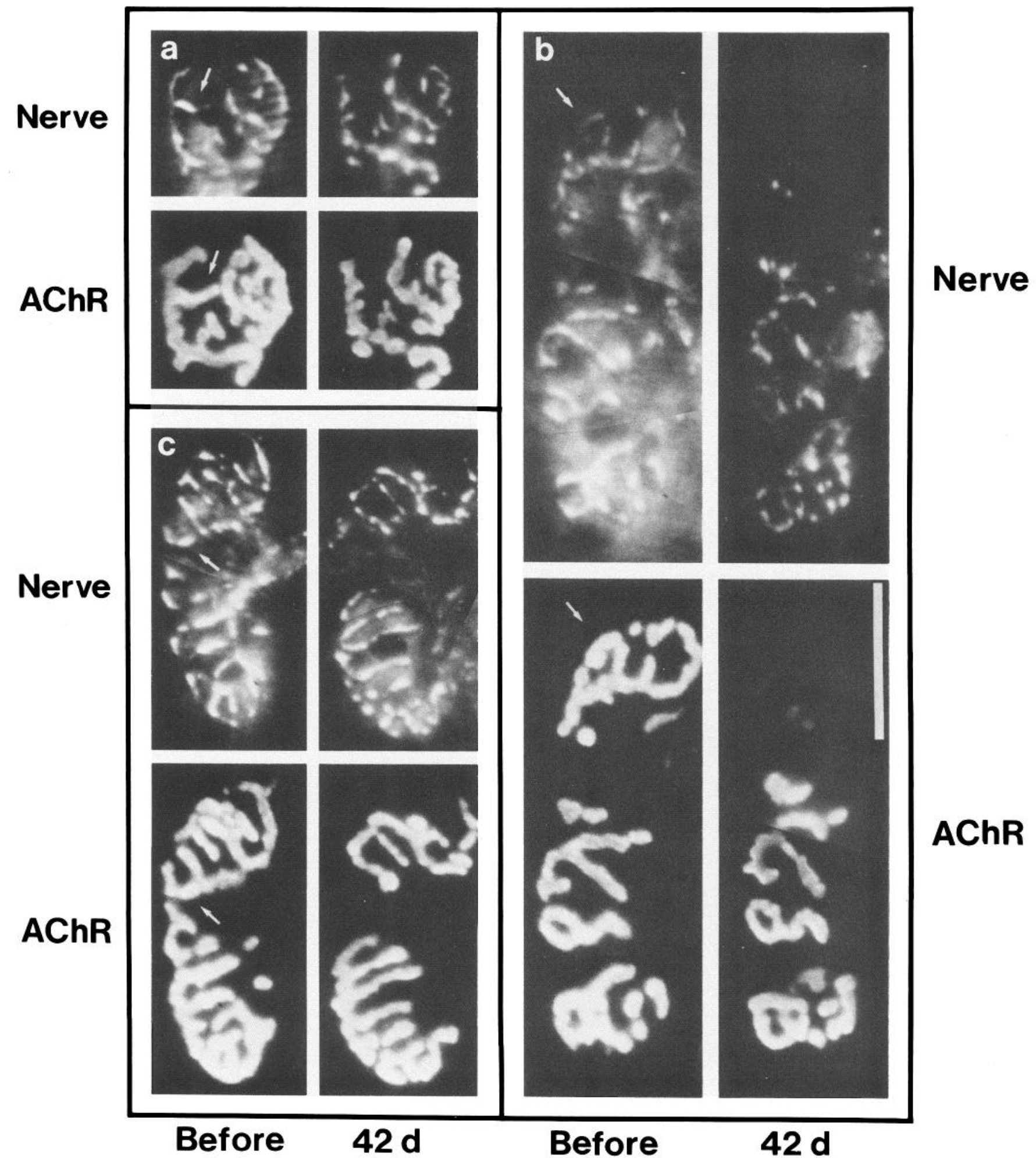

Figure 11. Sites at reinnervated endplates that lose ACh receptors and also lack overlying nerve terminals. Nerve terminal and ACh receptor distribution of 3 endplates $(a-c)$ viewed before and $42 \mathrm{~d}$ after the second crush of a double nerve crush lesion. For each endplate, the top row of pictures shows the nerve terminal stained each time with 4-Di-2-ASP and the bottom row, the ACh receptors stained with fluorescent $\alpha$-bungarotoxin. In each case, the region of the endplate that loses $\mathrm{ACh}$ receptors also lacks an overlying nerve terminal (arrows). Thus, a precise alignment between nerve terminal and receptors is maintained, even in endplates that change dramatically such as in panel $b$. Scale bar, $50 \mu \mathrm{m}$.

had been crushed twice. In such muscles, the majority (73\%) of the endplates should lose sites (see Sections 8 and 10). We found $7 \mathrm{~d}$ after the second nerve crush, when the axons had been back in the muscle for about $3 \mathrm{~d}$ and before endplates lose receptor sites (Section 11), that the majority $(27 / 35)$ of the endplates were completely reoccupied (i.e., the stained nerve terminal completely coincided with the receptor regions). Only $23 \%$ of the endplates had sites that had not been reoccupied. However, 
$70 \%$ of the endplates subsequently lose synaptic sites. This argues that lack of reoccupation cannot account for all the lost receptor sites. More directly, by viewing completely reoccupied endplates twice (at early and late stages of reinnervation), we found that many receptor regions that were reoccupied were subsequently lost ( $n=17$; Fig. 15 ).

To see if incomplete reoccupation was at least partly responsible for synapse loss, we obtained a further sample of 12 endplates that had areas of receptor unoccupied by nerve terminal at 7-8 d after the second nerve crush of a double crush lesion. In particular, we wanted to know if receptors were subsequently lost from the unoccupied regions. In 10 of these endplates the receptor site that was vacated at the first viewing had been completely reoccupied by the nerve at the second viewing without any loss of receptors from the site. In the 11 th endplate the receptor site was still unoccupied $9 \mathrm{~d}$ later but had not been eliminated. In the last endplate, most of the previously unoccupied region had been reoccupied by the second viewing while part of the region had been eliminated. From all of these studies, it appears that receptor regions unoccupied by nerve terminals are uncommon; when they occur, they often are transitory, with a nerve terminal subsequently reoccupying the site, and only very rarely is the unoccupied receptor site lost in such endplates. This suggests that incomplete reoccupation is not a major cause of receptor site disappearance.

\section{Prospective studies show selective receptor loss from transiently multiply innervated endplates}

The results discussed so far indicate a temporal relation between the duration of sprout regression and the duration of loss of nerve terminals and underlying $\mathrm{ACh}$ receptors during reinnervation. The incidence of transient multiple innervation by sprouts following various procedures also correlates with the percentage of endplates that lose synaptic sites following various nerve lesions. Moreover, control experiments have ruled out denervation per se and incomplete reoccupation as major causes of loss of ACh receptor sites. Taken together these observations strongly suggest that $\mathrm{ACh}$ receptor sites and overlying nerve terminals are lost only at endplates in which multiple axons converge and synapse elimination takes place.

For a direct test of the idea that synapse elimination is the driving force for the loss of synaptic sites, we undertook a prospective study of randomly selected reinnervated endplates prior to the time of synapse elimination ( $9 \mathrm{~d}$ after a single crush lesion to the nerve). Nine days after nerve crush is the time of peak multiple innervation (Fig. 1). Using 4-Di-2-ASP to stain nerve terminals, some of the endplates we viewed appeared to be multiply innervated, that is, they were clearly connected to a nearby endplate via a sprout and also innervated by an axon growing up the old Schwann cell tube. The receptor distributions of these potentially multiply innervated endplates were stained with rhodaminated $\alpha$-bungarotoxin and visualized, and the endplate locations were mapped. Of 44 randomly selected endplates viewed $9 \mathrm{~d}$ after a single nerve crush, 19 were connected to other endplates by one or more sprouts. Of these 19 endplates which appeared multiply innervated, however, only approximately half should actually be receiving a second input from the sprout (the other half are the source; see Materials and Methods for discussion). If postsynaptic receptor loss is caused by synaptic competition, then one would expect that approximately half of 19 apparently multiply innervated endplates would lose postsynaptic sites, and this was the case. In a blind study, 58\% (11/19) of the apparently multiply innervated endplates lost postsyn-

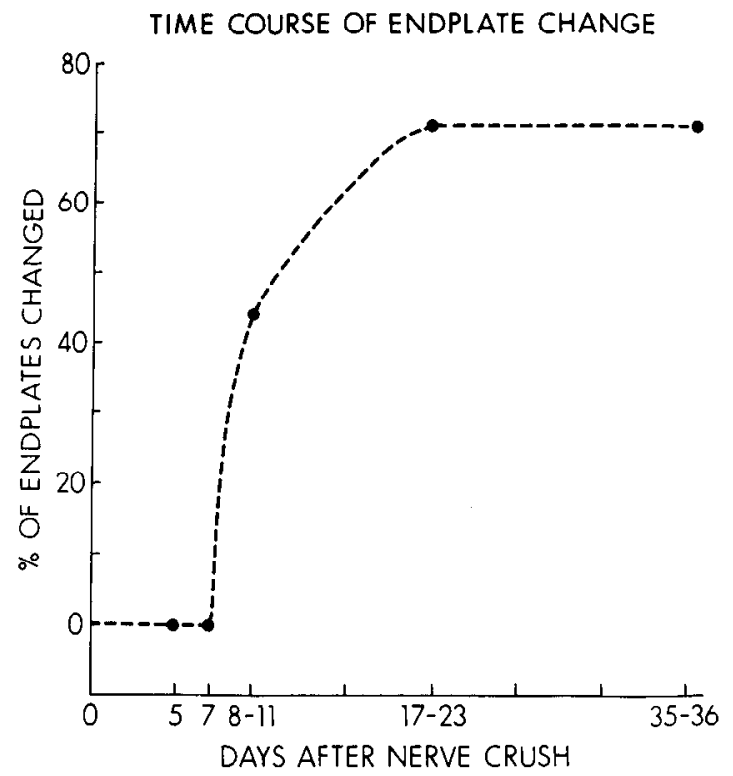

Figure 12. ACh receptor sites are lost only during the first 2 weeks after the return of axons to endplate sites. The percentage of endplates that have lost more than $10 \%$ of their ACh receptor sites is plotted against time after the sccond crush of a double ncrve crush lesion. Although the axons return to the endplate sites $4 \mathrm{~d}$ after the last nerve crush, no endplates lose receptor sites until $8 \mathrm{~d}(n=37)$. Starting at 8 $\mathrm{d}$, there is a rapid increase in the percentage of endplates that have lost receptor sites, such that by $17-23 \mathrm{~d}$ after nerve crush, $71 \%$ of the endplates have lost receptor areas. After this time, no new endplates lose postsynaptic regions because, at $35-36 \mathrm{~d}$, the same $71 \%$ of the endplates studied at 17-23 d are still missing the same receptor areas and no new changes were seen in any of the endplates $(n=28)$ (see also Fig. 14).

aptic receptor regions by the second viewing. The remaining 25 endplates chosen for study were not obviously enriched for multiple innervation: they did not have sprouts connecting them to other endplates or sprouts from the nerve, although they could be multiply innervated through the old Schwann cell tube. When we relocated these endplates we found signifiantly fewer changed endplates than in the previous group. Only $24 \%(6 / 25)$ of the unclassified endplates showed loss of postsynaptic receptors. The difference between the 2 groups of endplates was significant $\left(\chi^{2}=3.9 p<0.05\right)$. Thus, endplates that appear to be multiply innervated selectively lose postsynaptic $\mathrm{ACh}$ receptors during the period of synapse elimination. The overall percentage of endplates that lost postsynaptic sites in our prospective study of 44 randomly selected endplates (39\%) was not significantly different from the $29 \%$ of endplates that lose postsynaptic sites in nonprospective studies $\left(\chi^{2}=0.53, p>0.5\right)$. Thus, viewing endplates during the period of synapse elimination did not appear to alter the percentage of endplates that lost postsynaptic sites.

\section{Receptor elimination begins before nerve terminal elimination}

We were interested to know precisely when, during the period of receptor elimination, nerve terminals were eliminated from these same sites. In particular, does nerve terminal elimination precede or follow the lose of postsynaptic receptors? If nerve terminal loss precedes loss of postsynaptic receptors, then nerve loss should be followed by a reduction of receptor staining. This would mean that regions of endplates that are unoccupied by nerve terminal should lose underlying receptors. However, in 

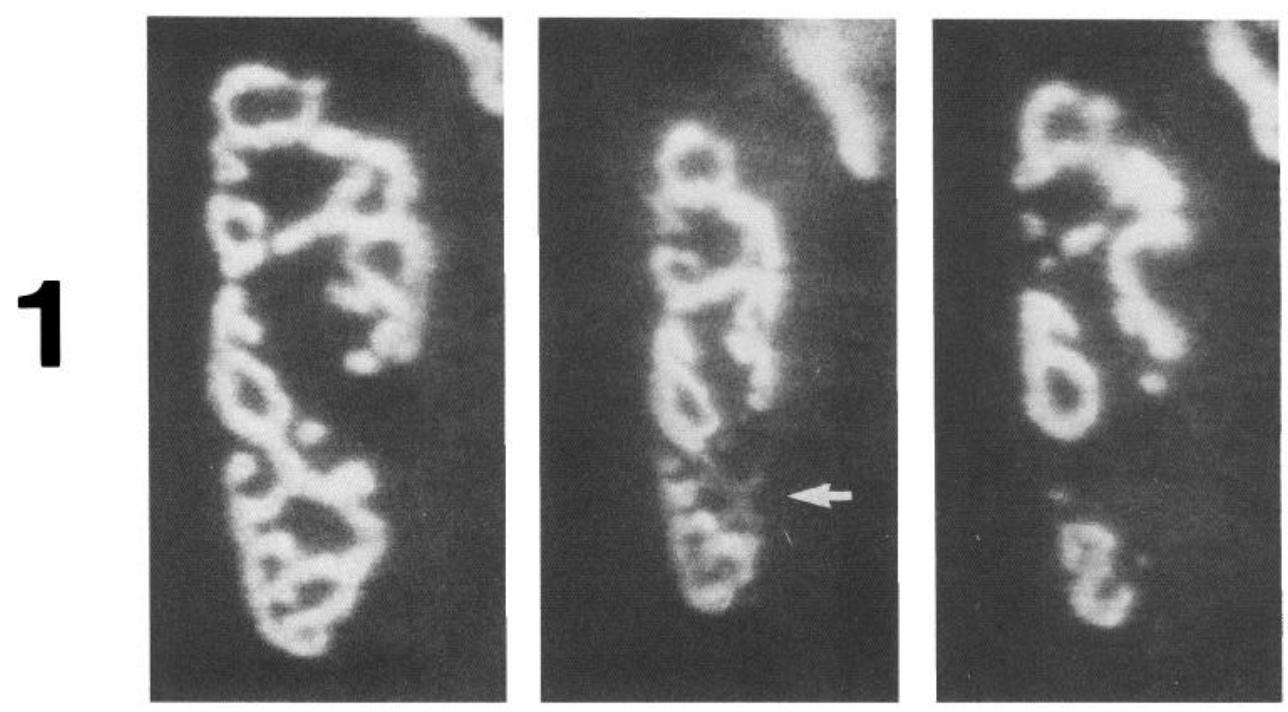

Figure 13. ACh receptor sites to be eliminated stain faintly before they are completely eliminated. The ACh receptor distribution of 2 endplates viewed before, and 8 and $18 \mathrm{~d}$ after the second of 2 nerve crushes in a double nerve crush lesion. At $8 \mathrm{~d}$ after nerve crush, receptor sites can be seen that stain less intensely (arrows). At $18 \mathrm{~d}$, these sites have been completely eliminated. Scale bar, $25 \mu \mathrm{m}$.

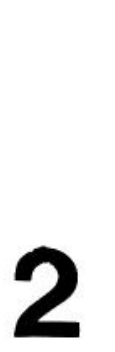

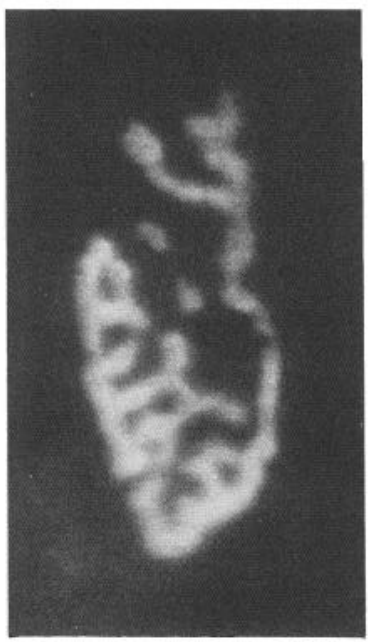

Before

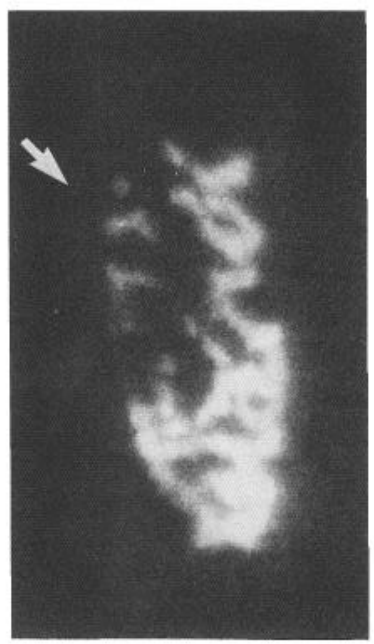

8 days

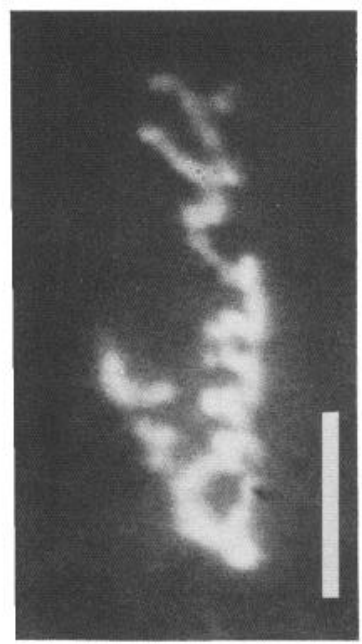

18 days those rare situations when we found receptor regions unoccupied by nerve terminals, these receptor sites were not subsequently eliminated (Section 12). Thus, we could find little evidence that receptor sites become faint due to loss of overlying nerve terminals.

If receptor loss was initiated so rapidly after nerve loss that unoccupied receptor regions nearly always appeared faint, the nerve should always be missing over regions of faint receptors. However, we found that in 13 out of 25 endplates with faint areas of receptor (in the process of being eliminated) 7-9 $d$ after double nerve crush, the area of faint receptors was occupied by nerve terminal. Thus, our data do not support the idea that receptor sites are faintly staining because the overlying nerve terminal has previously been eliminated.

Our data are more consistent with the loss of postsynaptic receptors preceding elimination of the nerve terminal because, as mentioned above, we could find areas of faint receptor (in the process of being eliminated) that were still occupied by nerve terminal. We followed 7 of those endplates over time. In 6 of the 7 endplates, the nerve terminal overlying the faint region was subsequently eliminated (Fig. 16) and the underlying re- ceptors disappeared entirely. The other endplate was unchanged $6 \mathrm{~d}$ later. Thus, in many cases, receptors clearly become faint before the nerve terminal is lost.

However, at many endplates with faint receptor regions, the faint regions were unoccupied by nerve terminal $(12 / 25$ at $7-9$ $d$ after double crush). These endplates probably represent a slightly later stage of synapse elimination when the overlying nerve terminal has already retracted. That is, receptors begin to disappear, the nerve terminals are eliminated, and finally, the receptors are completely eliminated.

If the above sequence of events occurs, it should be possible to find regions of faint receptor from which the nerve terminal is in the process of retracting. In particular, faintly staining receptor regions should occasionally be only partially occupied by nerve terminal. In 6 endplates at 7-9 d after double nerve crush we found areas in which nerve terminal only occupied part of the faint receptor region (Fig. 17). Moreover, the nerve terminals remaining over the faint receptors were far thinner than ordinary. The impression gained from these endplates was that the nerve terminal was in the process of being eliminated from the faint receptor regions. 

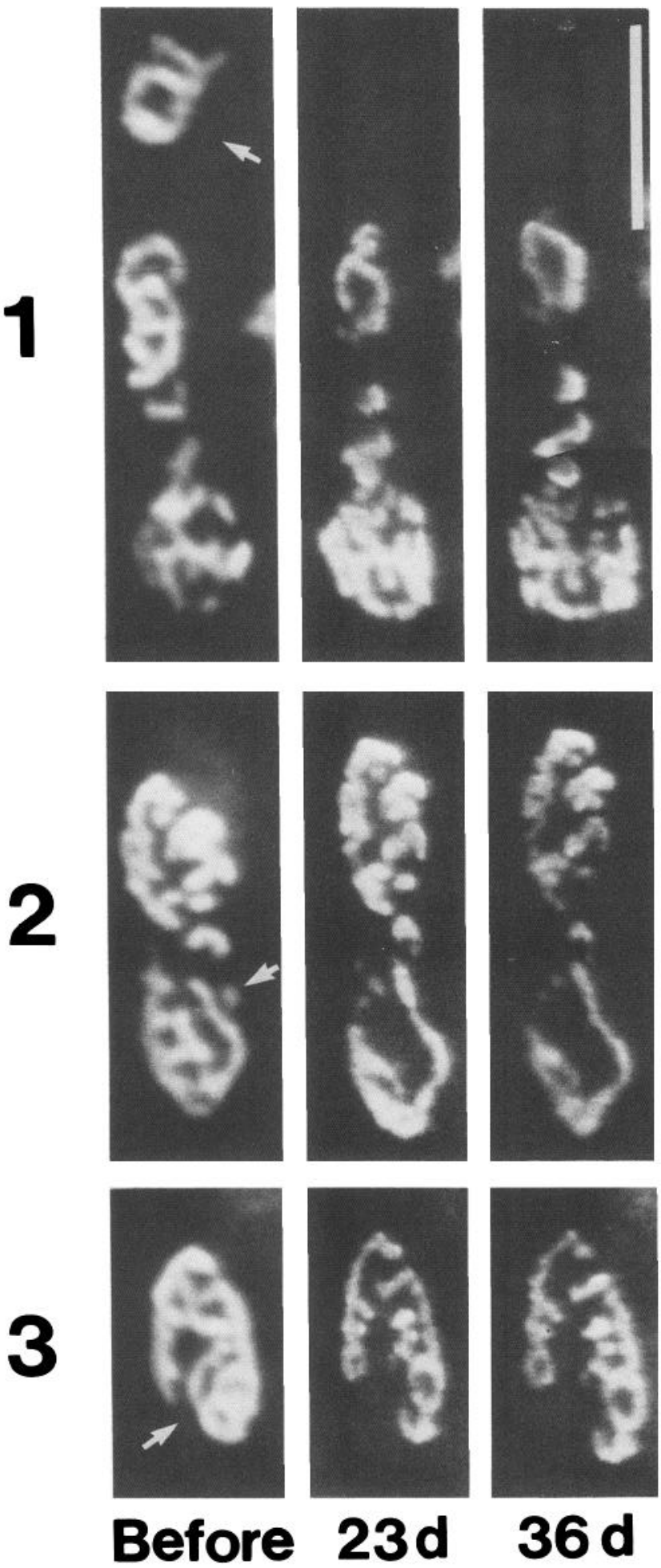

Figure 14. Endplates that lose ACh receptor sites are subsequently stable over time. ACh receptor distributions of endplates viewed before and at 2 times after the second of a double nerve crush lesion. The left column shows the appearance of each endplate prior to denervation, and the middle column shows the appearance of the endplate $23 \mathrm{~d}$ after the initial nerve crush. By $23 \mathrm{~d}$, each endplate has lost a region of receptors indicated by an arrow at the first view. Right column shows the appearance of each endplate $36 \mathrm{~d}$ after the initial nerve crush. The endplates do not continue to lose $\mathrm{ACh}$ receptor sites and are stable after the first 2 weeks following reinnervation. The only receptor loss seen between the second and third views is a small patch of receptors lost from the top of endplate 1 . Such continuing losses were small and rare. Scale bar, $50 \mu \mathrm{m}$.
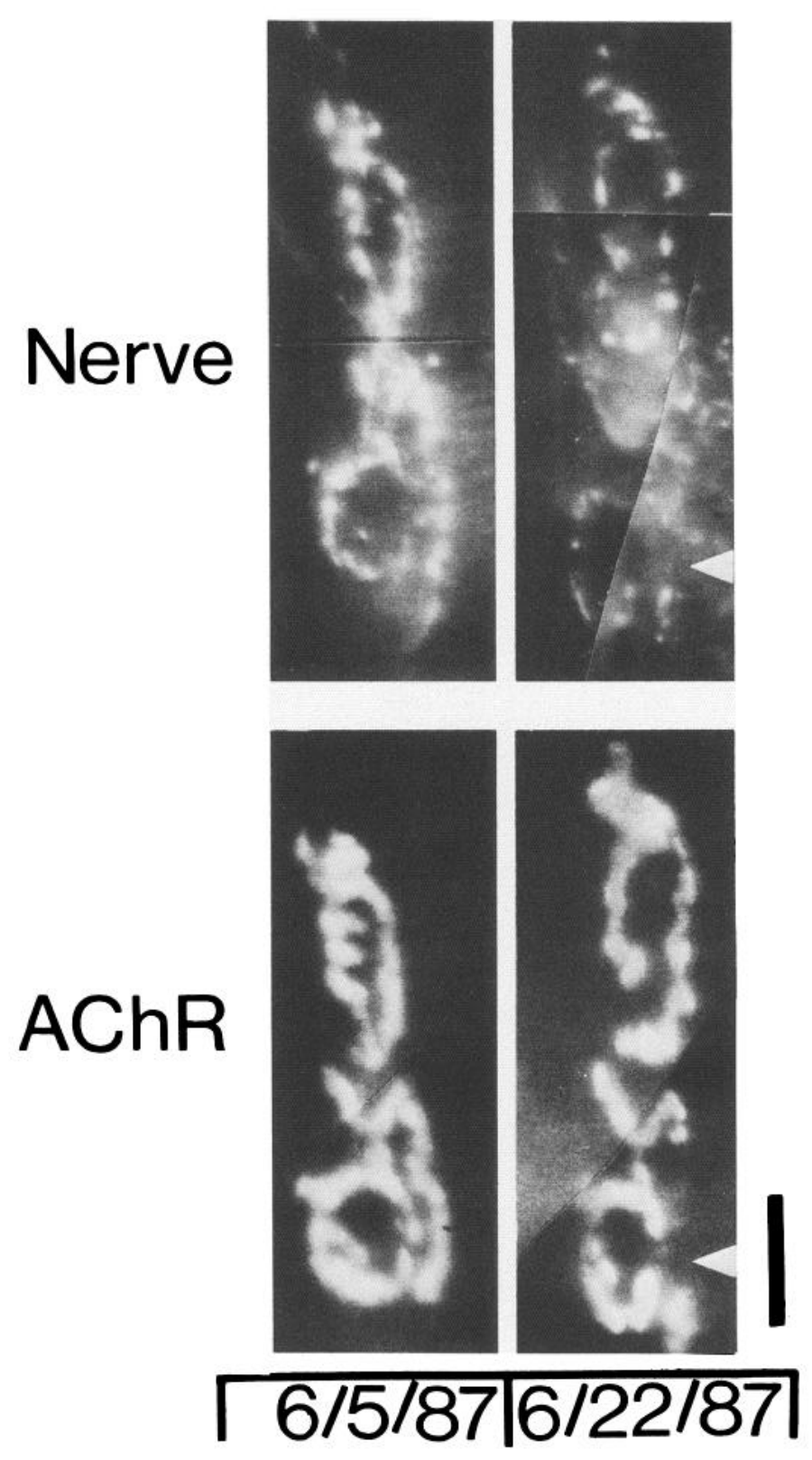

Figure 15. ACh receptor sites reoccupied by nerve terminal are subsequently lost during reinnervation. Nerve terminal and ACh receptor distribution of an endplate viewed 9 and $26 \mathrm{~d}$ after a single nerve crush. The top row of pictures shows the nerve terminal stained with 4-Di-2ASP at each time and the bottom row shows the ACh receptor distribution stained with fluorescently tagged $\alpha$-bungarotoxin. The arrows indicate a site of $\mathrm{ACh}$ receptor elimination that was temporarily occupied by a nerve terminal. Thus, this receptor loss cannot be due to incomplete reoccupation by reinnervation axons. Scale bar, $25 \mu \mathrm{m}$.

\section{Receptors are selectively removed from postsynaptic areas that are eliminated}

To better understand how postsynaptic receptor sites come to disappear, we viewed $\mathrm{ACh}$ receptors that were labeled prior to synapse elimination. Because rhodaminated $\alpha$-bungarotoxin binds essentially irreversibly to the ACh receptor, we were able to follow receptors for nearly 3 weeks after they were labeled (Heinemann et al., 1978; Reiness et al., 1978).

Receptors that were labeled before nerve crush were re-viewed $17 \mathrm{~d}$ later without adding new stain. At the second viewing, all 
Figure 16. Evidence that nerve terminal elimination follows receptor loss. $\mathrm{ACh}$ receptor sites begin to be eliminated before the overlying nerve terminal is lost. The nerve terminal and ACh receptor distribution of the endplate region was viewed $9 \mathrm{~d}$ and $18 \mathrm{~d}$ after a double nerve crush lesion. $A$, Low-power view of the endplate showing the faint region of receptor staining at top of the endplate (arrow) $9 \mathrm{~d}$ after double nerve crush which is subsequently eliminated. $B$, Higher-power views of the overlying nerve terminal and the faintly staining receptor region shown in $A$. At $9 \mathrm{~d}$ after nerve crush, the lightly staining receptor region is still occupied by brightly staining nerve terminal. At $19 \mathrm{~d}$, the receptor staining is completely gone, and virtually all of the nerve terminal staining has also been eliminated. Scale bar: $A, 30 \mu \mathrm{m} ; B, 15$ $\mu \mathrm{m}$.

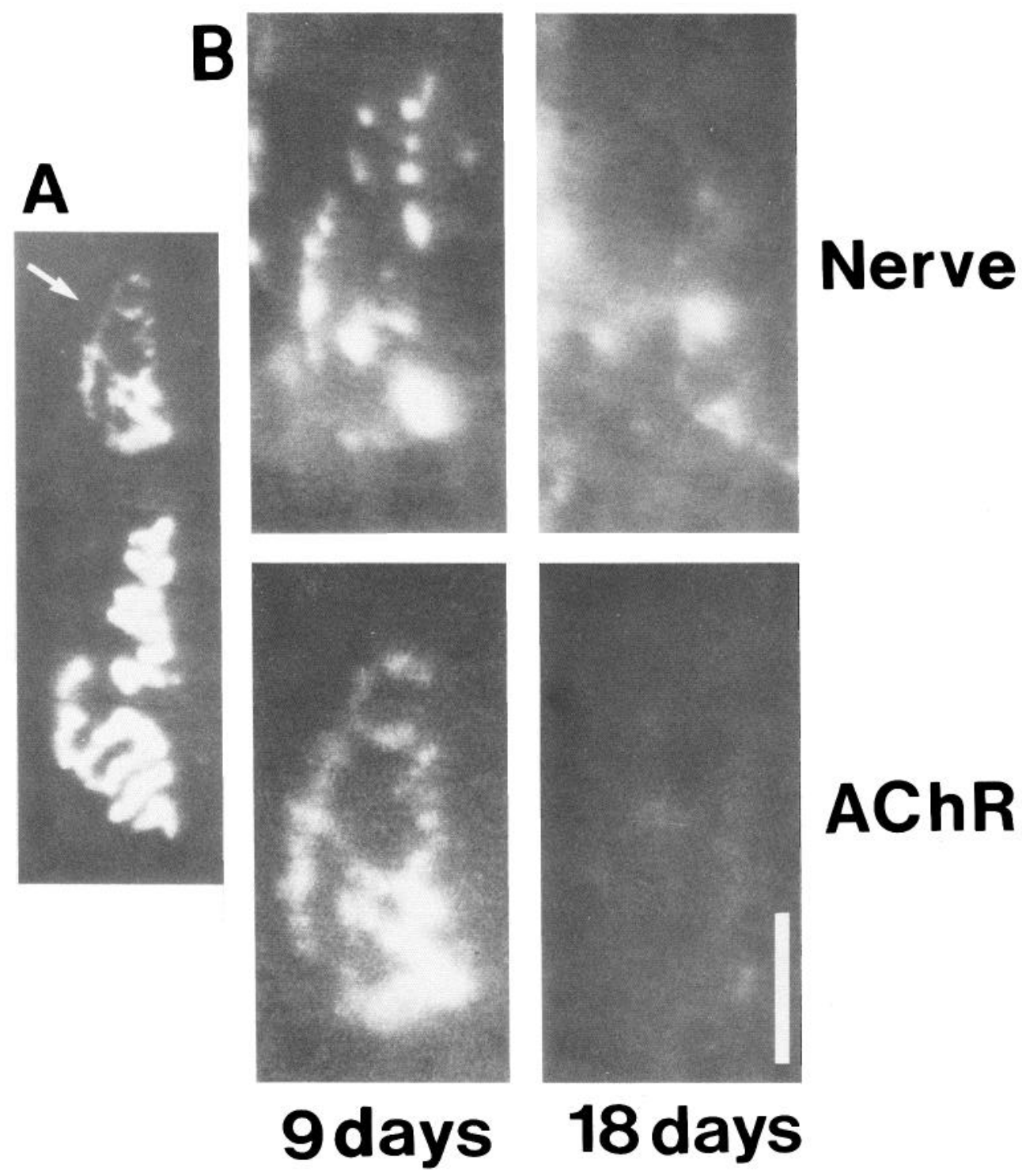

the endplate sites were lightly stained due to $\mathrm{ACh}$ receptor turnover, but clearly there were regions from which receptors were entirely absent (Fig. 18). Receptors inserted into the membrane after the first viewing were then stained by adding new fluorescent $\alpha$-bungarotoxin. The new bungarotoxin did not stain the sites that had selectively lost old receptors but stained all the other sites. The receptor distribution of each endplate was the same whether the old or newly inserted receptors were visualized. Thus, the eliminated receptor areas had not incorporated new receptors. These results indicate that postsynaptic sites are eliminated both by the lack of insertion of new receptors and a selective removal of receptors already inserted into the muscle fiber membrane.

\section{One synaptic basal lamina marker does not remodel during synapse elimination}

Because it is known that nerve terminals can be maintained on basal lamina ghosts (Sanes et al., 1978), the basal lamina may be a repository for the information regulating selective nerve maintenance and elimination. We thus also wished to know

Figure 17. A nerve terminal that appears to be in the process of retracting from a faint receptor region. $A$, The receptor distribution of an endplate prior to nerve crush. $B$, The receptor distribution of the same endplate $9 \mathrm{~d}$ after a double crush nerve lesion. The arrow indicates a faintly staining region of receptors in the middle of the endplate. $C$. The appearance of the nerve terminal $9 \mathrm{~d}$ after double nerve crush. The axon(s) can be seen entering the endplate from the right. The curved arrow indicates a nerve terminal that is still over the faintly staining receptor region shown in $B$. The nerve terminal that is still over faint receptor is abnormal in appearance: It is thin and does not stain as brightly as other regions. This appearance suggests that it may be in the process of retracting. The straight arrow indicates a region underlain by faint receptors from which the nerve has already retracted. $D$, Nerve terminal and receptor distribution of the endplate superimposed. The nerve terminal pictured in $C$ is shown in green and is superimposed on an enlarged image of the receptor distribution shown in $B$, the receptors being shown in red. Areas where nerve terminal overlies receptor are yellow. The axon(s) can again be seen entering from the right and are green. The curved arrow indicates an area where nerve terminal is still over the faintly staining receptor region. The straight arrow indicates a faintly staining region of receptor (see $B$ ) that is unoccupied by nerve terminal. Scale bar: $A$ and $B, 25 \mu \mathrm{m} ; C$ and $D, 15 \mu \mathrm{m}$. 

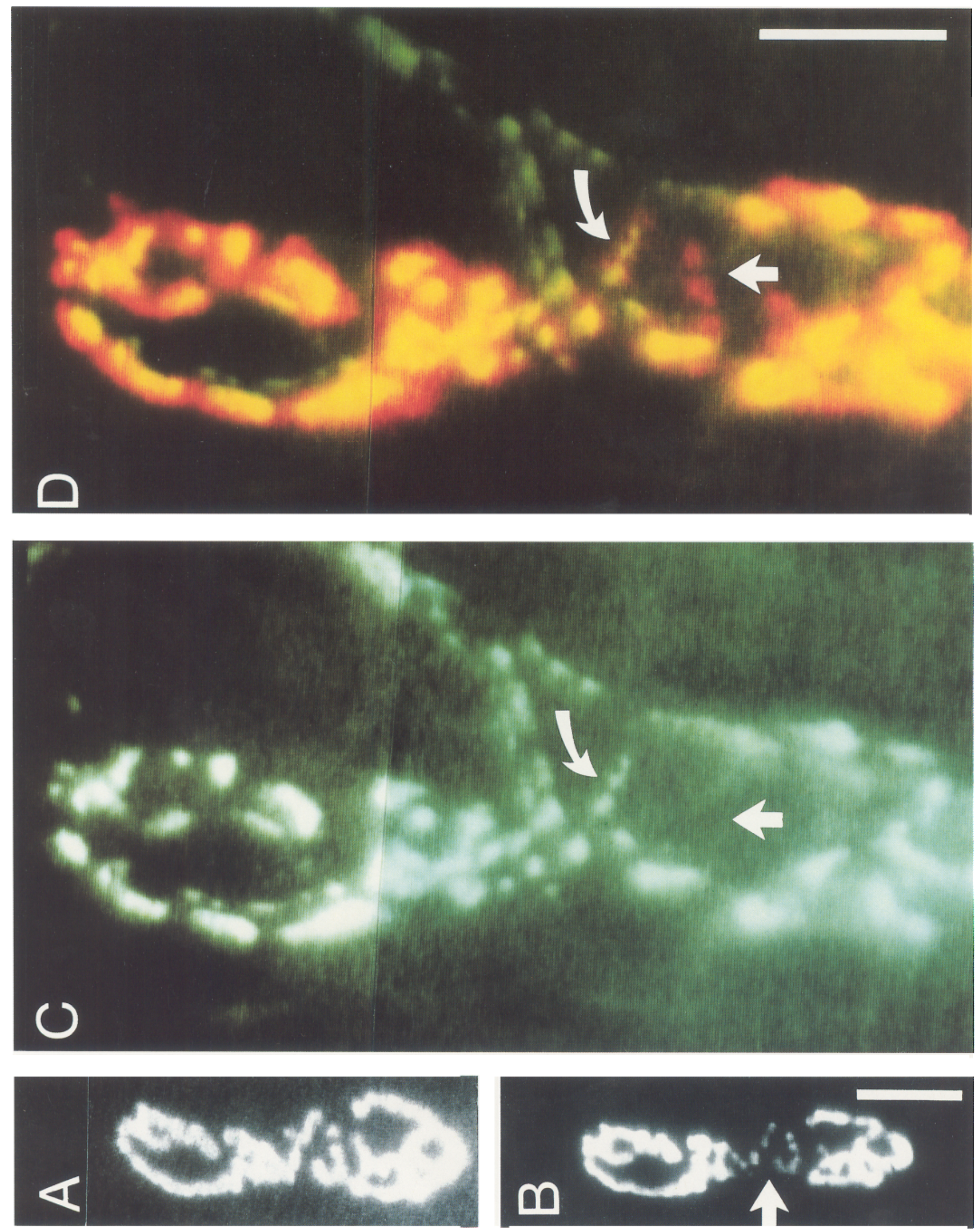

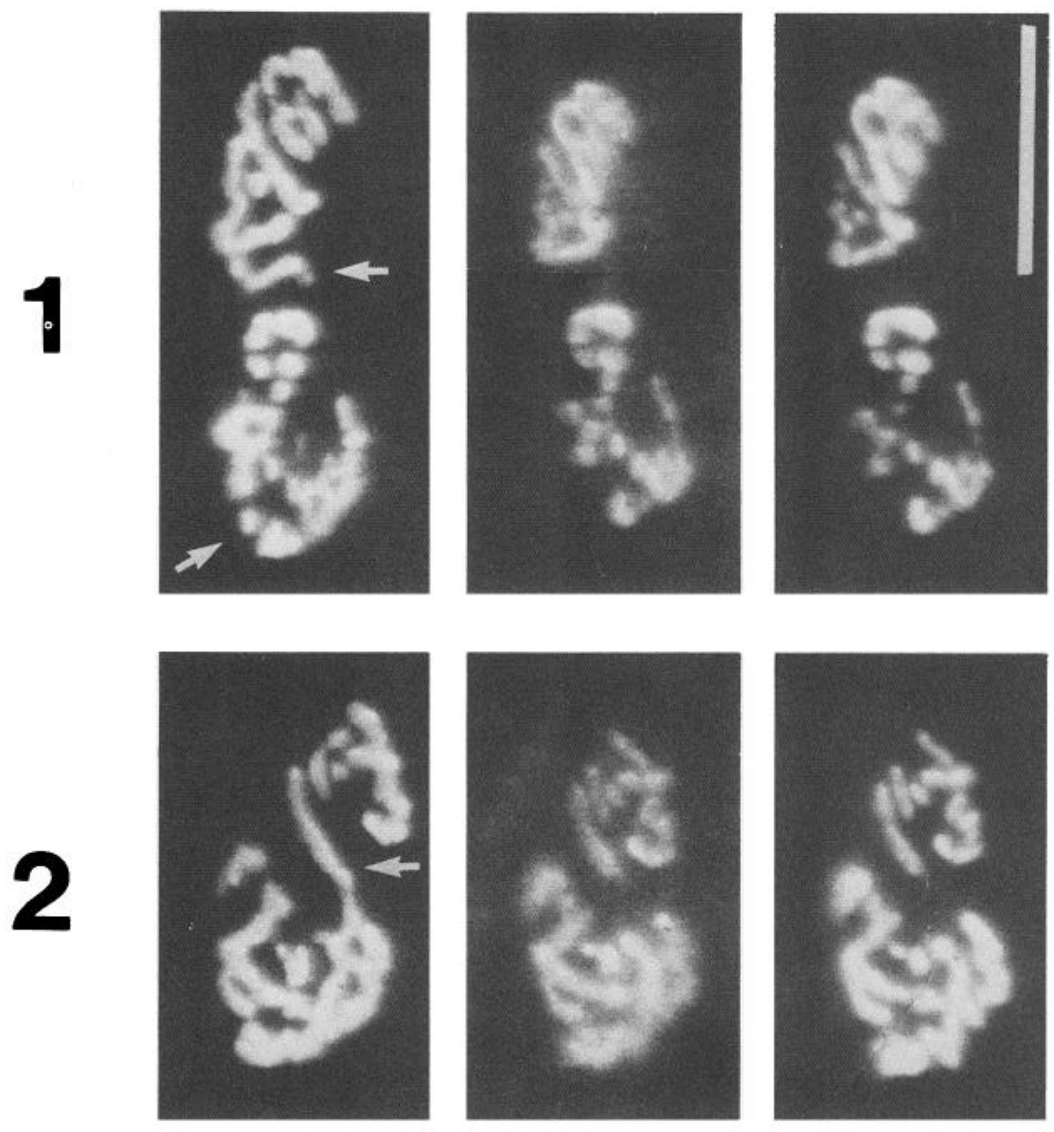

Figure 18. ACh receptors already inserted in the muscle membrane are selectively eliminated from synaptic sites. The ACh receptor distributions of 3 endplates is shown before and $17 \mathrm{~d}$ after a single nerve crush. The left column shows the appearance of the endplates before nerve crush; the middle column shows the distribution of receptors stained at the first viewing $17 \mathrm{~d}$ later; and right column shows the appearance of the endplates after the application of new rhodaminated bungarotoxin at 17 d. Arrows in the views at left indicate areas from which receptors are subsequently selectively eliminated. The right column shows that no newly synthesized receptors are present at these sites at the second viewing. Thus, receptor loss is due to both selective elimination and lack of new receptor insertion. Scale bar, $50 \mu \mathrm{m}$.

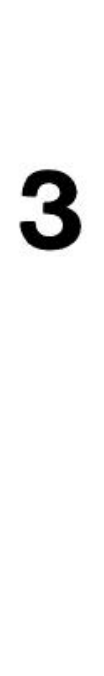

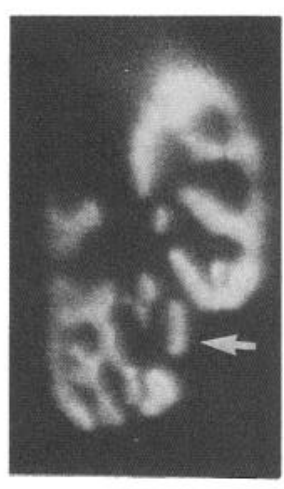

$5 / 19 / 87$

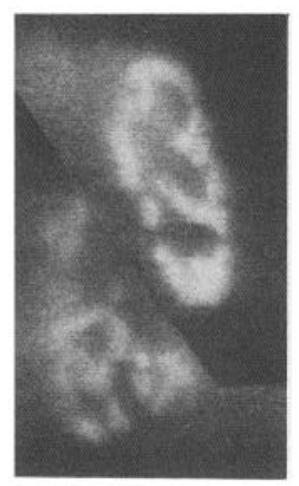

$6 / 5 / 87$

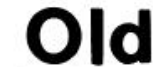
AChR

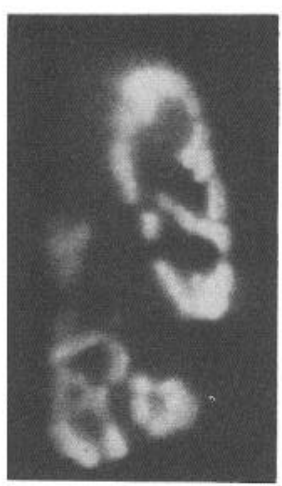

$6 / 5 / 87$ New AChR when and if the intervening basal lamina begins to change during the process of synapse elimination. We followed the staining pattern of cholinesterase as a basal lamina marker (McMahan et al., 1978) during the period of synapse elimination following double nerve crush. It was not necessary to stain the cholinesterase itself both before and after nerve crush, because the cholinesterase colocalizes with $\alpha$-bungarotoxin binding sites in normal muscle (Fig. 19). We therefore stained postsynaptic sites with rhodaminated $\alpha$-bungarotoxin and photographed endplates prior to double crush of the nerve. Twelve days after the second crush, the receptors were restained with rhodaminated $\alpha$-bungarotoxin to find areas beginning to lose receptors. Cholinesterase in the basal lamina was then stained using an antibody and a fluorescently tagged secondary antibody (see Materials and Methods). We were surprised to find that cholinesterase sites were still evident and well stained even over areas in the process of losing postsynaptic receptors (Fig. 20). At this stage, nerve terminals had also generally been eliminated from the faint receptor regions. In fact, sites of eliminated nerve terminals could be appreciated just by viewing the pattern of cholinesterase staining. At reinnervated endplates the cholinesterase was found in 2 distributions: some was still present in 

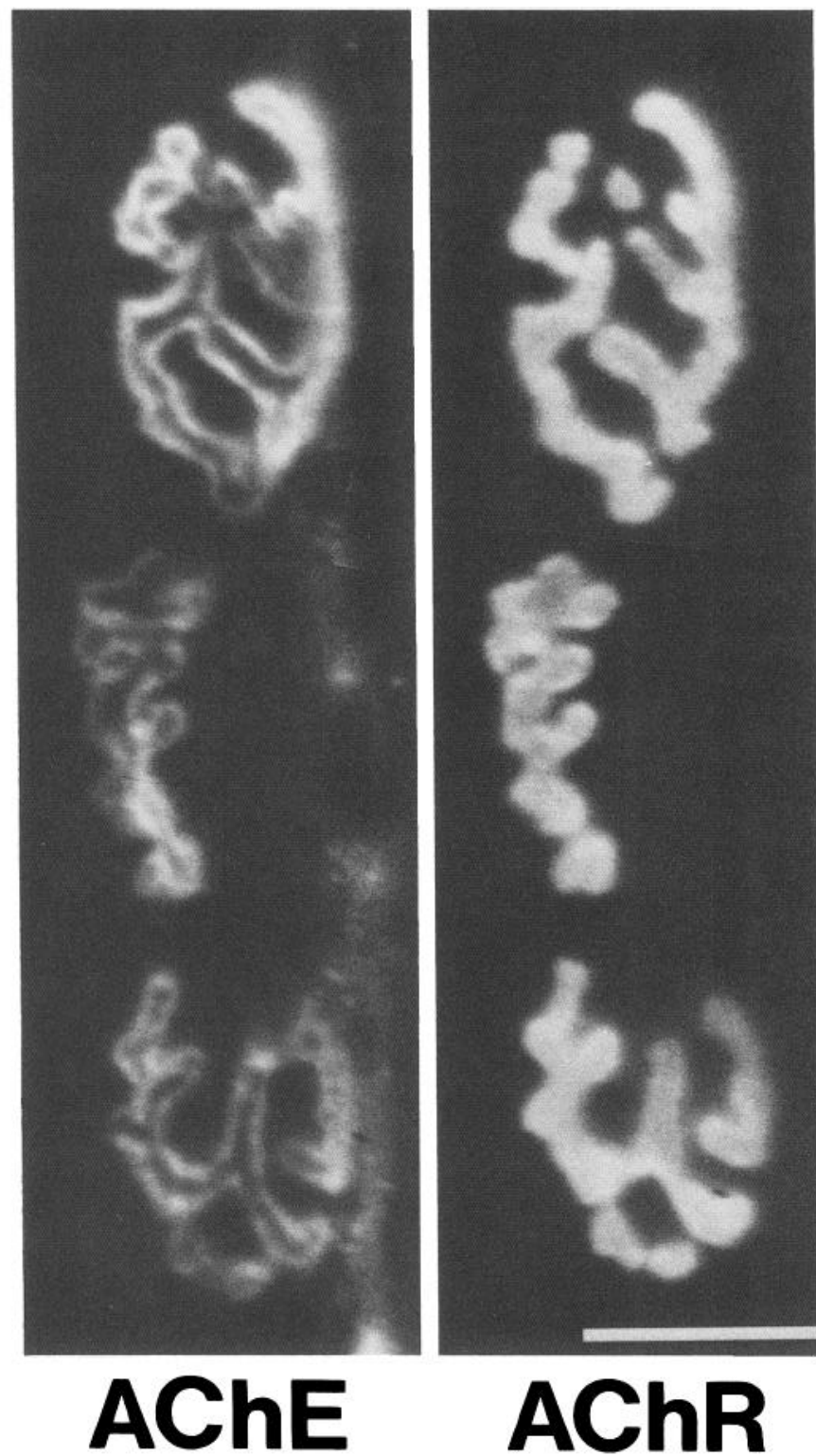

Figure 19. Acetylcholinesterase (AChE) and ACh receptor distributions line up precisely in normal mouse muscle. The $\mathrm{AChE}$ and receptor distributions at an endplate in normal muscle are shown. Although the appearance of the 2 stains is different, cholinesterase staining as 2 parallel lines and bungarotoxin as a solid line, the stains line up perfectly. The parallel line staining of cholinesterase is due to the presence of nerve terminal (Letinsky et al., 1976; Wernig et al., 1980). Scale bar, $25 \mu \mathrm{m}$.

the typical "railroad track" pattern (see, for example, Fig. 19), indicating the presence of a nerve that prevents cholinesterase staining within the synaptic cleft (Letinsky et al., 1976; Wernig et al., 1980). These were overlying brightly stained ACh receptor regions. In areas of faintly stained $\mathrm{ACh}$ receptors, however, instead of the 2 lines, regions of a continuous wider band of more brightly staining cholinesterase were now present (Fig. 20), indicating the loss of the overlying nerve terminal (Letinsky et al., 1976; Wernig et al., 1980). Thus, both receptor loss and nerve terminal elimination precede cholinesterase loss at synaptic sites.

At very long intervals following reinnervation (up to $77 \mathrm{~d}$ ), the cholinesterase was still present and appeared unchanged in

\section{AChR \\ AChR \\ AChE}
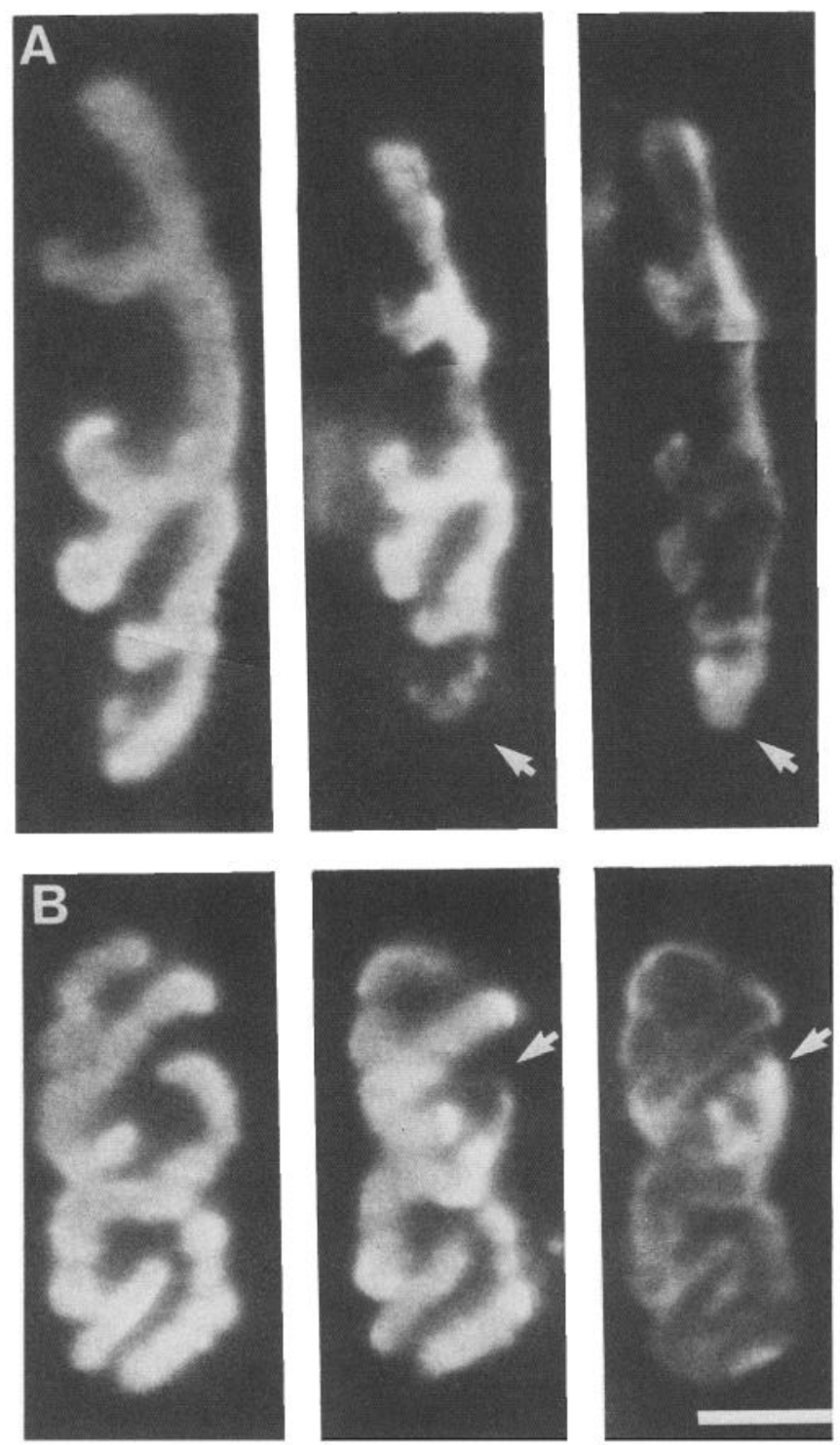

\section{Before}

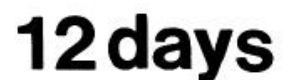

\section{2days}

Figure 20. Loss of ACh receptors precedes any loss of cholinesterase staining. The ACh receptor distribution of 2 endplates $(A$ and $B)$ shown before and $12 \mathrm{~d}$ after a double crush lesion. At the second time, the cholinesterase distribution of the endplates was also visualized. The left column shows the receptor distribution of each endplate before nerve crush; the middle column shows the receptor distribution $12 \mathrm{~d}$ after the last nerve crush (arrows indicate areas being eliminated); and the right column shows the appearance of the cholinesterase staining $12 \mathrm{~d}$ after the last nerve crush. Cholinesterase still stains at sites where receptors are being eliminated. In fact, the cholinesterase staining at sites losing receptors is brighter than elsewhere and continuous, rather than consisting of 2 parallel lines. This is consistent with the nerve terminal being eliminated from these areas (Letinsky et al., 1976; Wernig et al., 1980). Scale bar, $25 \mu \mathrm{m}$.

areas from which $\mathrm{ACh}$ receptors and nerve were missing (Fig. 21). Thus, this basal lamina marker changes much more slowly (if at all) than the overlying nerve terminal or the underlying receptors. 
AChR

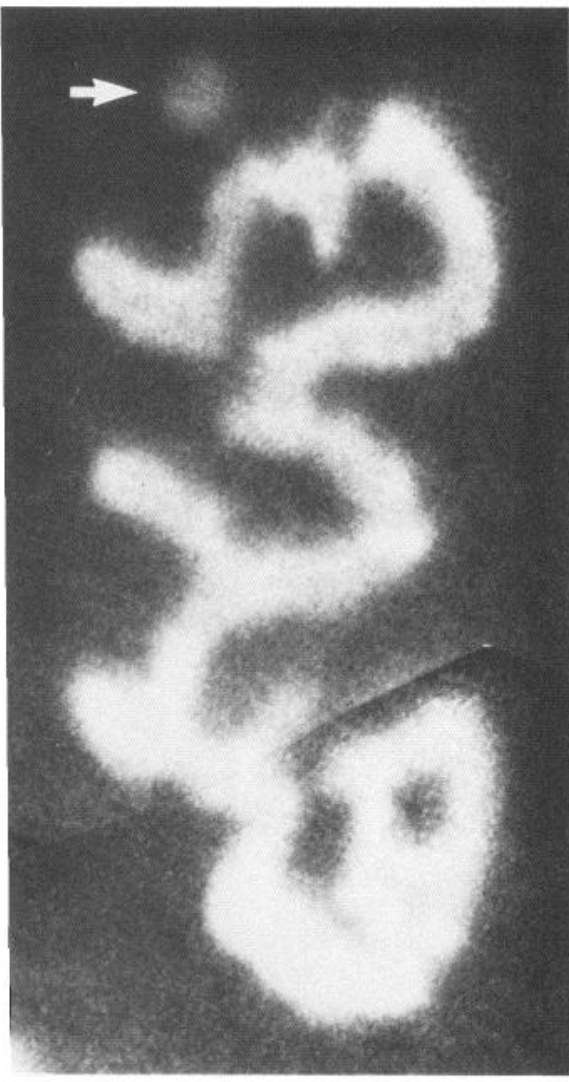

Before
AChR
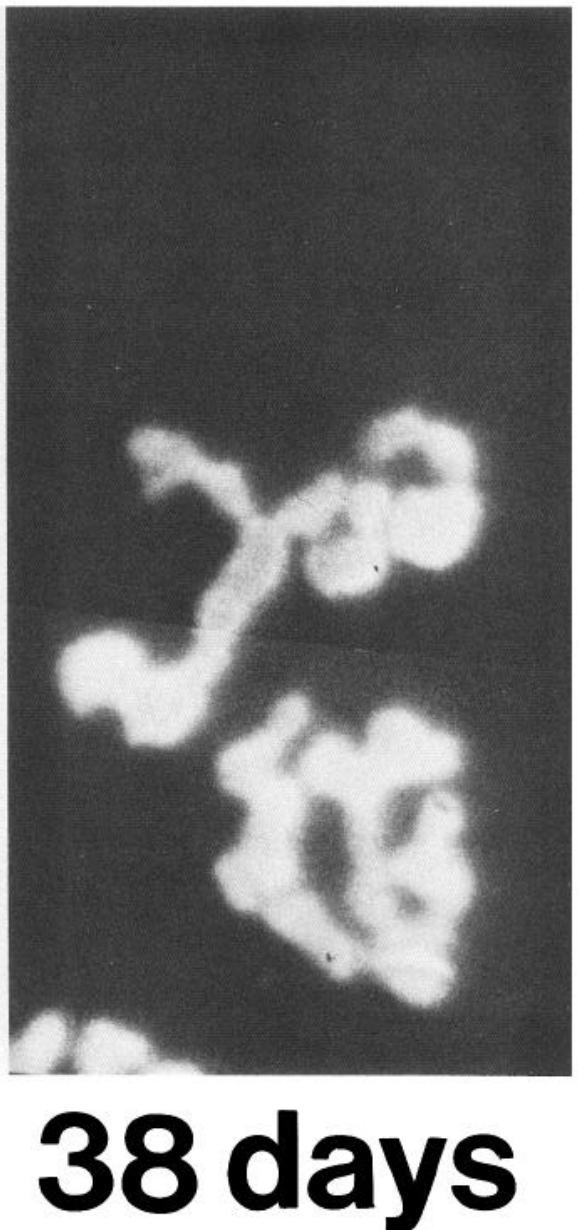

AChE

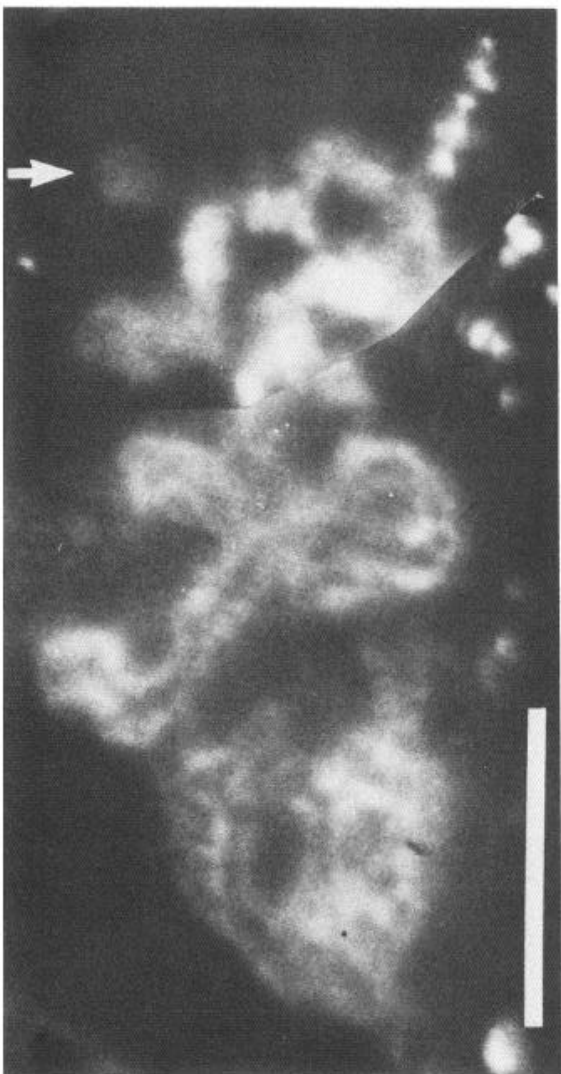

38 days

Figure 21. Cholinesterase staining is still present in its original configuration long after receptor and nerve terminal are eliminated from synaptic sites. The ACh receptor distribution of an endplate region viewed before and $38 \mathrm{~d}$ after reinnervation. At the second time, the cholinesterase distribution was also visualized. The left column shows the appearance of the receptor distribution prior to nerve crush, and the middle column shows the appearance of the receptors at the second viewing. The upper region of receptors, including a small region indicated by the arrow, at the first time has been eliminated. The right column shows the cholinesterase distribution at the second time. Cholinesterase staining is still present over the receptor area that has been eliminated, including the small region (arrow). The cholinesterase staining in the region that has lost receptors is continuous rather than consisting of parallel lines, indicating loss of overlying nerve terminal. Scale bar, $25 \mu \mathrm{m}$.

\section{Discussion}

The results reported here make a number of points about reinnervation and synapse elimination.

1. Reinnervating motor axons accurately reoccupy the previous synaptic sites on muscle fibers. This idea is not new. Letinsky et al. (1976) and Lullman-Rauch (1971) have argued that former synaptic sites are reoccupied in amphibians and mammals, respectively. Other workers have, however, suggested that some new synaptic endings are established near, but not overlying, former synaptic sites (Iwayama, 1969; Bennett et al., 1973; Jansen and Van Essen, 1975). In this work we have for the first time directly tested whether nerve terminals accurately reoccupy former sites by viewing the same endplate sites before and after reinnervation. Our results demonstrate that endplate sites are accurately reoccupied. The precise reoccupation is striking because the branching of the terminal axon may be quite different at the reinnervated endplates. This indicates that the synaptic sites within the endplate, and not the pathway to them, retain the information for accurate reinnervation. We also found that during reinnervation, new sites are almost never established. The finding that no new sites are established is somewhat surprising given the profusion of sprouts present at early times in reinnervation. These sprouts, however, are almost never maintained (see also Gorio et al., 1983).

2. The reoccupation is not always stable because some reoccupied sites become vacant during the period of synapse elimination that follows reinnervation. This work argues that while there are stable markers that make synaptic sites especially attractive to axons, the interactions that occur during synapse elimination cause vacation of some of these sites perhaps by removing synaptic markers. This work confirms earlier studies showing synapse elimination following reinnervation of adult muscle (McArdle, 1975; Gorio et al., 1983; Werle and Herrera, 1986). During reinnervation the developmental transition from multiple to single innervation is recapitulated, indicating that 
the factors governing synapse elimination still operate at the adult neuromuscular junction. We show that when multiple axons are present on a reinnervated muscle fiber they converge on the same endplate site that was innervated before denervation. Thus, the competition between axons that eliminates multiple innervation takes place, as in development, within the close confines of one endplate site. The manner in which muscle fibers are multiply innervated, however, is different from that in development. In development, multiple axons appear to enter an endplate through the same Schwann cell sheath, and sprouts are only rarely seen going from one endplate to another (Riley, 1977; O’Brien et al., 1978; Morrison-Graham, 1983). During reinnervation, in contrast, muscle fibers often become multiply innervated by the growth of terminal sprouts between adjacent endplate sites. These sprouts regress and synaptic contacts are lost at roughly the time physiological measures of multiple innervation are declining.

We have extended previous studies by directly viewing synaptic sites in living animals during the period of synapse elimination. By looking at the same endplate at 2 intervals after reinnervation, we have been able to visualize the elimination of synaptic boutons at some endplates. The loss of boutons was associated both spatially and temporally with the loss of a secondary input from a sprout entering the endplate.

3. Following reinnervation, some endplates lose a portion of their receptor-rich regions, and these regions underlie eliminated nerve terminals. Our results argue that these changes are related to synaptic competition because (1) they occur during the period of axon withdrawal, (2) they occur preferentially on endplates that appear multiply innervated, and (3) the incidence of thcse changes correlates with the incidence of endplates undergoing synapse elimination following various procedures. Furthermore, alternative explanations for the dramatic loss of pre- and postsynaptic sites - such as the technique used to view endplates on multiple occasions, denervation per se, and incomplete reoccupation of endplate sites-were shown not to give rise to the loss seen. Postsynaptic changes paralleling synapse elimination had not previously been demonstrated. These changes may indicate that the postsynaptic cell is involved in competitive synaptic reorganization, perhaps playing a crucial role in the process.

One technical issue requires special note. The use of bungarotoxin to follow receptors may block neuromuscular transmission and thus affect reinnervation. In particular, the loss of nerve terminals and underlying receptors might be induced by this blockade. There are a number of results, however, that essentially rule out this possibility. First, in normal muscle we show that bungarotoxin $(4 \mu \mathrm{g} / \mathrm{ml}$ for $3 \mathrm{~min})$ does not induce any change in terminal or receptor distribution (Fig. 6). Second, in reinnervation experiments, the percentage of receptors still labeled when the nerve returns is much less than the $50 \%$ labeled initially (Levitt and Salpeter, 1981). Thus, blockade was very unlikely during the period of synapse elimination. Finally, loss of synapses occurred even in the total absence of bungarotoxin (see, for example, Fig. 5).

Taking the work on receptor changes together with our work on nerve terminals during reinnervation, we conclude that during reinnervation of the mouse sternomastoid muscle the following events take place. About $4 \mathrm{~d}$ after the nerve to the sternomastoid is crushed within a few millimeters of the muscle, axons begin to reoccupy previous endplate sites. Over the following week most endplates become completely reoccupied, usually precisely reestablishing the original endplate shape. The only major difference is that now many endplate sites are multiply innervated, often by sprouts which connect neighboring endplates. During the 2nd and 3rd week after the nerve has returned, these sprouts regress and physiological signs of multiple innervation decrease. During this period both nerve terminal and postsynaptic receptor sites disappear from regions of many endplates. Once the period of synapse elimination is complete, endplates that have lost regions of nerve terminal and underlying receptor stop changing.

At most of the endplates in which loss was observed, it appeared that the eliminated terminals occupied a region that was smaller than the remaining axon's territory. This might mean that when 2 axons occupy the same endplate, the axon with the smaller synaptic area is at a competitive disadvantage. Alternatively, our results do not rule out the possibility that following elimination, part of the vacated postsynaptic site is reoccupied by the remaining axon. If this were the case, the permanently vacated territory may not reveal the full extent of the area initially occupied by the losing axon.

4. The eliminated sites appear to be no longer attractive to axons. Even at long periods, former sites remain unoccupied and $\mathrm{ACh}$ receptors are not inserted. In this way, a transient event such as synapse elimination leaves a permanent mark on the structure of the synapse. This is thus a direct demonstration of a transient event in the nervous system leading to a change in synaptic structure that is subsequently maintained for long periods of time.

5. ACh receptors in the postsynaptic membrane begin to be eliminated from endplate sites before nerve terminals are removed. Before obvious changes can be detected in nerve terminals that will be eliminated or changes can be observed in basal lamina cholinesterase, there is a significant decrease in postsynaptic receptor staining from sites that will subsequently undergo synapse elimination. The significance of postsynaptic receptor loss prior to nerve terminal loss is that it suggests the postsynaptic cell anticipates the loss of nerve terminals and may play an important role in instigating that loss.

An important caveat in interpreting this work is that the absence of visual evidence of presynaptic change prior to changes in postsynaptic receptor density does not necessarily mean that the postsynaptic cell in fact changes first. It is possible, for example, that a branch of a nerve terminal stops functioning (e.g., due to branch block failure) before postsynaptic changes in receptor density occur. Our conclusions are thus limited by the availability, at present, of visual evidence of synaptic integrity. Taken at face value, however, the results do argue for a very carly involvement of the postsynaptic cell in synapse climination. Indeed, it would be surprising if postsynaptic receptor elimination occurred so rapidly and yet was not involved in some important way in synapse elimination. We know that receptors are maintained at the endplate even in the absence of nerves for very long periods (Frank et al., 1975; Steinbach, 1981; see Fig. 10). Only after axons reoccupy an endplate site do receptors begin to be eliminated.

The early loss of ACh receptors might have functional effects on synaptic transmission at the soon-to-be-eliminated synapse. If the terminal were still functioning, the synaptic potential amplitude might be limited by the decrease in receptors. This decrease should occur not by a diminution in quantal content, but rather by a smaller depolarization per quantum. It is interesting that one study of synapse elimination (Taxt et al., 1983) noted a class of small miniature endplate potentials during the period of synapse elimination. Although this result may have been due 
to the recording technique (Soha et al., 1987), it suggests that physiological evidence for imminent synapse elimination may be obtainable.

An obvious question is how one axon might initiate the loss of postsynaptic receptor molecules underlying another axon? Although such a mechanism is speculative in reinnervation, during development nerve terminals can induce the lateral migration of receptors in the plane of the membrane so that they come to lie underneath the nerve terminal (Anderson and Cohen, 1977; Ziskind-Conhaim ct al., 1984; sce also Frank and Fischbach, 1979). If a similar mechanism operated during synaptic competition, it could account for the elimination of receptors from a synaptic site (see Fig. 18). Thus, the "winning" axon might eliminate receptors underlying the "losing" axon by causing them to migrate away and come to reside under its own terminals.

What remains entirely unclear, however, is how (or even if) the postsynaptic receptor itself is involved in nerve terminal maintenance. Work in developing systems argues that functional blockade of $\mathrm{ACh}$ receptors does not inhibit synapse formation (Anderson and Cohen, 1977; Cohen, 1980; Rubin et al., 1980). Our work argues similarly in adults that partial blockade with bungarotoxin does not interfere with synaptic maintenance. On the other hand, evidence that sprouting is inhibited by $\alpha$-bungarotoxin argues that blocking receptors may inhibit synapse formation (Pestronk and Drachman, 1978, 1985; see, however, Holland and Brown, 1980). Because the receptor is such a complex molecule, it is, of course, possible that it subserves nerve maintenance functions that are independent of the ACh binding site. It is conceivable that receptors are important in the maintenance of nerve terminals and that, in their absence, nerve terminals are not maintained.

It is also possible that a molecule or molecules that are closely associated and colocalize with $\mathrm{ACh}$ receptors are, in fact, the relevant agents in nerve terminal maintenance. It is important to emphasize that we have selectively viewed receptors because of the availability of an excellent ligand ( $\alpha$-bungarotoxin).

If postsynaptic molecules are necessary for nerve terminal maintenance, then their elimination should cause the rapid loss of nerve terminals. In support of this idea, we have recently found that when mouse muscle fibers are caused to degenerate without nerve damage, the nerve terminals rapidly regress from basal lamina ghosts (Rich and Lichtman, 1987, and unpublished observations; see, however, Yao, 1986).

In frogs, much evidence indicates that nerve terminals are constantly in the process of elaboration and elimination (Wernig et al., 1980; Herrera and Banner, 1987). The absence of ACh receptors at sites abandoned by nerve terminals has been interpreted as the effect of the absence of a presynaptic factor (see, for example, Anzil et al., 1984). The present results, however, suggest an alternative explanation in which the muscle induces the overlying nerve terminal elimination and not vice versa.

In summary, the early loss of postsynaptic receptors under nerve terminals that will subsequently be eliminated may offer a clue to the mechanism of synapse elimination in this situation. Rather than competition occurring between axons vying for occupation of the same postsynaptic site (as has been suggested in frogs; see, for example, Morrison-Graham, 1983), competition causes the permanent loss of a synaptic site and both the nerve terminal and underlying postsynaptic receptors are eliminated. The manner in which one axon instigates the loss of another axonal terminal remains unclear. The early loss of post- synaptic receptors underlying soon-to-be-eliminated terminals suggests that an axon may use the postsynaptic cell as an intermediary in its competition with another axon. The cellular basis of competition may be the depletion of relevant synaptic molecules by one axon from postsynaptic sites under a competing axon.

\section{References}

Anderson, M. J., and M. W. Cohen (1977) Nerve-induced and spontaneous redistribution of acetylcholine receptors on cultured muscle cells. J. Physiol. (Lond.) 268: 757-773.

Anzil, A. P., A. Bieser, and A. Wernig (1984) Light and electron microscopic identification of nerve terminal sprouting and retraction in normal adult frog muscle. J. Physiol. (Lond.) 350: 393-399.

Balice-Gordon, R. J., and J. W. Lichtman (1987) The relationship between pre- and postsynaptic elements during synaptic competition at developing neuromuscular junctions. Soc. Neurosci. Abstr. 13:374.

Barstad, J. A. B., and G. Lilleheil (1968) Transversely cut diaphragm preparation from rat. Arch. Int. Pharmacodyn. 175: 373-390.

Bennett, M. R., E. M. McLachlan, and R. S. Taylor (1973) The formation of synapses in reinnervated mammalian striated muscle. $\mathrm{J}$. Physiol. (Lond.) 233: 481-500.

Breedlove, S. M., R. J. Balice-Gordon, and J. W. Lichtman (1988) Neuromuscular junction alterations in an androgen sensitive muscle. Soc. Neurosci. Abstr. 14: 1209.

Brown, M. C., J. K. S. Jansen, and D. Van Essen (1976) Polyneuronal innervation of skeletal muscle in new-born rats and its elimination during maturation. J. Physiol. (Lond.) 261: 387-422.

Changeux, J. P., and A. Dauchin (1976) Selective stabilization of developing synapses as a mechanism for the specification of neuronal networks. Nature 264: 705-712.

Cohen, M. W. (1980) Development of an amphibian neuromuscular junction in vivo and in culture. J. Exp. Biol. 89: 43-56.

Connold, A. L., J. V. Evers, and G. Vrbova (1986) Effect of low calcium and protease inhibitors on synapse elimination during postnatal development in the rat soleus muscle. Dev. Brain Res. 28: 99-107.

Ding, R., J. K. S. Jansen, N. G. Laing, and H. Tonnesen (1983) The innervation of skeletal muscles in chickens curarized during early development. J. Neurocytol. 12: 887-919.

Duxson, M. J. (1982) The effect of postsynaptic block on development of the neuromuscular junction in postnatal rats. J. Neurocytol. 11: 395-408.

Fambrough, D. M. (1981) Denervation: Cholinergic receptors of skeletal muscle. In Receptor and Recognition Series, Vol. 13, R. J. Lefkowitz, ed., pp. 125-142, Chapman and Hall, London.

Frank, E., and G. D. Fischbach (1979) Early events in neuromuscular junction formation in vitro: Induction of acetylcholine receptor clusters in the postsynaptic membrane and morphology of newly formed synapses. J. Cell Biol. 83: 143-158.

Frank, E., J. K. S. Jansen, T. Lomo, and R. H. Westgaard (1975) The interaction between foreign and original motor nerves innervating the soleus muscle of rats. J. Physiol. (I ond.) 247: 725-743.

Gorio, A., G. Carmignoto, M. Finesso, P. Polato, and M. G. Nunzi (1983) Muscle reinnervation. II. Sprouting, synapse formation and repression. Neuroscience 8: 403-416.

Heinemann, S., J. Merlie, and J. Lindstrom (1978) Modulation of acetylcholine receptor in rat diaphragm by anti-receptor sera. Nature 274: 65-68.

Herrera, A. A., and L. R. Banner (1987) Direct observation of motor nerve terminal remodelling in living frogs. Soc. Neurosci. Abstr. 13: 1665.

Holland, R. L., and M. C. Brown (1980) Postsynaptic transmission block can cause terminal sprouting of a motor nerve. Science 207: 649-651.

Iwayama, I. (1969) Relation of regenerating nerve terminals to original endplates. Nature 224: 81-82.

Jansen, J. K. S., and D. C. Van Essen (1975) Reinnervation of rat skeletal muscle in the presence of $\alpha$-bungarotoxin. J. Physiol. (Lond.) 250: 651-667.

Kiernan, J. A. (1981) Histological and Histochemical Methods: Theory and Practice, Pergamon, Oxford, UK. 
Ko, P. K., M. J. Anderson, and M. W. Cohen (1977) Denervated skeletal muscle fibers develop discrete patches of high acetylcholine receptor density. Science 196: 540-542.

Kuffler, D. P., W. Thompson, and J. K. S. Jansen (1980) The fate of foreign endplates in cross-innervated rat soleus muscle. Proc. R. Soc. London [Biol.] 208: 189-222.

Letinsky, M. S., K. H. Fischbeck, and U. J. McMahan (1976) Precision of reinnervation of original postsynaptic sites in frog muscle after a nerve crush. J. Neurocytol. 5: 691-718.

Levitt, T. A., and M. M. Salpeter (1981) Denervated endplates have a dual population of junctional acetylcholine receptors. Nature 291. $239-241$.

Lichtman, J. W. (1980) On the predominantly single innervation of submandibular ganglion cells in the rat. J. Physiol. (Lond.) 302: 121130.

Lichtman, J. W., R. S. Wilkinson, and M. M. Rich (1985) Multiple innervation of tonic endplates revealed by activity-dependent uptake of fluorescent probes. Nature 314: 357-359.

Lichtman, J. W., L. Magrassi, and D. Purves (1987) Visualization of neuromuscular junctions over periods of several months in living mice. J. Neurosci. 7: 1215-1222.

Lullman-Rauch, R. M. (1971) The regeneration of neuromuscular junctions during spontaneous reinnervation of the rat diaphragm. $\mathrm{Z}$. Zellforsch. 121:593-603.

Magrassi, L., D. Purves, and J. W. Lichtman (1987) Fluorescent probes that stain living nerve terminals. J. Neurosci. 7: 1207-1214.

McArdle, J. J. (1975) Complex end-plate potentials at the regenerating neuromuscular junction of the rat. Exp. Neurol. 49: 629-638.

McMahan, U. J., J. R. Sanes, and L. M. Marshall (1978) Cholinesterase is associated with the basal lamina at the neuromuscular junction. Nature 27 1: 172-174.

Morrison-Graham, K. (1983) An anatomical and clectrophysiological study of synapse elimination at the developing frog neuromuscular junction. Dev. Biol. 99: 298-311.

O'Brien, R. A. D., A. J. Ostberg, and G. Vrbova (1978) Observations on the elimination of polyneuronal innervation in developing mammalian skeletal muscle. J. Physiol. (Lond.) 282: 571-582.

O'Brien, R. A. D., A. J. C. Ostberg, and G. Vrbova (1984) Protease inhibitors reduce the loss of nerve terminals induced by activity and calcium in developing rat soleus muscles in vitro. Neuroscience 12 : 637-646.

Oda, K. (1984) Age changes of motor innervation and acetylcholine receptor distribution on human skeletal muscle fibres. J. Neurol. Sci. 66: 327-338.

Pestronk, A., and D. B. Drachman (1978) Motor nerve sprouting and acetylcholine receptors. Science 199: 1223-1225.

Pestronk, A., and D. B. Drachman (1985) Motor nerve terminal outgrowth and acetylcholine receptors: Inhibition of terminal outgrowth by $\alpha$-bungarotoxin and anti-Acetylcholine receptor antibody. J. Neurosci. 5: 751-758.

Purves, D. (1977) The formation and maintenance of synaptic connections. In Function and Formation of Neural Systems, G. S. Stent, ed., pp. 21-49. Dahlem Konferenzen, Berlin.

Purves, D., and J. W. Lichtman (1985) Principles of Neural Development, Chap. 12, Sinauer, Sunderland, MA.

Ravdin, P., and D. Axelrod (1977) Fluorescent tetramethyl rhodamine derivatives of alpha-bungarotoxin: Preparation, separation and characterization. Anal. Biochem. 80: 585-592.
Redfern, P. A. (1970) Neuromuscular transmission in new-horn rats. J. Physiol. (Lond.) 209: 701-709.

Reiness, C. G., C. G. Weinberg, and Z. W. Hall (1978) Antibody to acetylcholine receptor increases degradation of junctional and extrajunctional receptors in adult muscle. Nature 274: 68-70.

Rich, M. M., and J. W. Licthman (1986) Remodelling of endplate sites during muscle reinnervation in the living mouse. Soc. Neurosci. Abstr. 12: 390

Rich, M. M., and J. W. Lichtman (1987) Effect of muscle fiber degeneration on the maintenance of identified nerve terminals in the living mouse. Soc. Neurosci. Abstr. 13: 573.

Riley, D. A. (1977) Multiple innervation of fiber types in the soleus muscles of postnatal rats. Exp. Neurol. 5: 400-409.

Robbins, N., and J. Polak (1988) Forms of growth and retraction at mouse neuromuscular junctions revealed by a new nerve terminal stain and correlative electron microscopy. Soc. Neurosci. Abstr. 13 1007.

Rotshenker, S., and U. J. McMahan (1976) Altered patterns of innervation in frog muscle after denervation. J. Neurocytol. 5: 719730.

Rubin, L. L., S. M. Schuetze, C. L. Weill, and G. D. Fischbach (1980) Regulation of acetylcholinesterase appearance at neuromuscular junctions in vitro. Nature 283: 264-267.

Sanes, J. K., L. M. Marshall, and U. J. McMahan (1978) Reinnervation of muscle fiber basal lamina after removal of myofibers. J. Cell Biol. 78: 176-198.

Soha, J. M., C. Yo, and D. C. Van Essen (1987) Synapse elimination by fiber type and maturational state in rabbit soleus muscle. Dev. Biol. 123: 136-144.

Srihari, T., and G. Vrbova (1978) The role of muscle activity in the differentiation of neuromuscular junctions in slow and fast chick muscles. J. Neurocytol. 7: 529-540.

Steinbach, J. H. (1981) Neuromuscular junctions and $\alpha$-bungarotoxin binding sites in denervated and contralateral cat skeletal muscles. J. Physiol. (Lond.) 313: 513-528.

Tate, K., and R. A. Westerman (1973) Polyneuronal self-reinnervation of a slow twitch muscle (soleus) in the cat. Proc. Aust. Phys. Pharm. Soc. 4: 174-175.

Taxt, T., R. Ding, and J. K. S. Jansen (1983) A note on the elimination of polyneuronal innervation of skeletal muscles in neonatal rats. Acta Physiol. Scand. 117: 557-560.

Thompson, W. (1983) Synapse elimination in neonatal rat muscle is sensitive to pattern of muscle use. Nature 302: 614-615.

Thompson, W. (1985) Activity and synapse elimination at the neuromuscular junction. Cell. Mol. Neurobiol. 5: 167-182

Werle, M. J., and A. A. Herrera (1986) The elimination of excess polyneuronal innervation in reinnervated adult frog muscles. Soc Neurosci. Absir. 12: 547

Wernig, A., M. Pecót-Dechavassine, and H. Stovër (1980) Sprouting and regression of the nerve at the frog neuromuscular junction in normal conditions and after prolonged paralysis with curare. J. Neurocytol. 9: 277-303.

Yao, Y. M. (1986) Factors that influence the stabilization of regenerating motor axon terminals in the adult frog. Soc. Neurosci. Abstr. 12: 13 .

Ziskind-Conhaim, L., I. Geffen, and Z. W. Hall (1984) Redistribution of acetylcholine receptors on developing rat myotubes. J. Neurosci. 4: $2346-2349$ 